\title{
Using Artificial Neural Networks to Predict Formation Stresses for Marcellus Shale with Data from Drilling Operations
}

\author{
Mousa S. Mohamed Abusurra
}

Follow this and additional works at: https://researchrepository.wvu.edu/etd

\section{Recommended Citation}

Abusurra, Mousa S. Mohamed, "Using Artificial Neural Networks to Predict Formation Stresses for Marcellus Shale with Data from Drilling Operations" (2017). Graduate Theses, Dissertations, and Problem Reports. 5023.

https://researchrepository.wvu.edu/etd/5023

This Thesis is protected by copyright and/or related rights. It has been brought to you by the The Research Repository @WVU with permission from the rights-holder(s). You are free to use this Thesis in any way that is permitted by the copyright and related rights legislation that applies to your use. For other uses you must obtain permission from the rights-holder(s) directly, unless additional rights are indicated by a Creative Commons license in the record and/ or on the work itself. This Thesis has been accepted for inclusion in WVU Graduate Theses, Dissertations, and Problem Reports collection by an authorized administrator of The Research Repository @ WVU. For more information, please contact researchrepository@mail.wvu.edu. 


\title{
USING ARTIFICIAL NEURAL NETWORKS TO PREDICT FORMATION STRESSES FOR MARCELLUS SHALE WITH DATA FROM DRILLING OPERATIONS
}

\author{
Mousa S. Mohamed Abusurra \\ Thesis submitted \\ to the Benjamin M. Statler College of Engineering and Mineral Resources \\ at West Virginia University \\ in partial fulfillment of the requirements for the degree of \\ Master of Science in \\ Petroleum and Natural Gas Engineering
}

Ilkin Bilgesu, Ph.D., Chair

Samuel Ameri, M.S.

Kashy Aminian, Ph.D.

Department of Petroleum and Natural Gas Engineering

Morgantown, West Virginia

2017

Keywords: Marcellus shale, Geomechanical properties, Hydraulic fracturing, Artificial neural networks

Copyright 2017 Mousa Abusurra 


\section{Abstract \\ USING ARTIFICIAL NEURAL NETWORKS TO PREDICT FORMATION STRESSES FOR MARCELLUS SHALE WITH DATA FROM DRILLING OPERATIONS}

\section{Mousa S. Mohamed Abusurra}

Artificial neural networks have been applied to different petroleum engineering disciplines. This is contributed to the powerful prediction capability in complex relationships with enough data available. The objective of this study is to develop a new methodology to predict the vertical and horizontal stresses using artificial neural networks for Marcellus shale well laterally drilled in Monongalia County, WV.

This approach coupled the drilling surface measurements with the recorded well logging data. Drilling parameters included depth, WOB, RPM, standpipe pressure, torque, pump flow rate and rate of penetration. Well logging data included gamma ray and bulk density. The model output was the minimum horizontal stress and vertical stress. The well trajectory was divided into two main parts, the vertical and lateral section since the change in the drilling direction along with changing structural geology and sedimentation impacted the resultant stresses.

Several neural networks were designed with different number of feedforward backpropagation architectures. The collected data was filtered and normalized before neural networks were trained using part of data. A percentage of the data was used to validate the trained model. Finally, a blind data set aside was used to test the model prediction accuracy and to estimate error percentages. Preliminary results show that adding logging data such as gamma ray and bulk density improves the model accuracy. Also, increasing the number of hidden layers and neurons improved the efficiency. However, higher the number of neurons and hidden layers higher was the computational cost due to increased model convergence time.

The correlation coefficients of the predicted and observed values ranged between 0.76 and 0.99 . This approach is beneficial regarding hydraulic fracturing design and fracture orientation prediction in unconventional shales. 


\section{Dedication}

Dedicated to my dear God, without Him guiding me in every step, nothing would be possible for me. This is also dedicated to my father Salem Abusurra who's presence would make this achievement even more special. Also, I would like to present this to my beloved mother Fatima Omar Mousa whose constant sacrifices give me a better life and led me to this point. 


\section{ACKNOWLEDGEMENT}

I would like to express my deepest thanks and appreciations to my research advisor Dr. Ilkin Bilgesu for his continuous support and encouragement throughout this research. His contributions are numerous and valuable. I would also like to thank all members of my research committee for their guidance and helpful suggestions. I heartily appreciate the support and advice from Professor Sam Ameri, Chair of Petroleum and Natural Gas Engineering Department. He has been a father and friend throughout my study. My thank is to my academic advisor Dr. Kashy Aminian for his support and advice and special thanks to all family of Petroleum and Natural Gas Engineering Department especially to Ms. Beverly Matheny for her friendly ambiance and continuous help. My sincere appreciation also goes to my family and friends for their unconditional love, support, advice, and prayers.

Also, I would like to acknowledge that the data used in this research was funded through the U.S.DOE National Energy Technology, Marcellus Shale Energy and Environmental Laboratory (MSEEL) (DOE Award No.: DE-FE0024297). 


\section{TABLE OF CONTENTS}

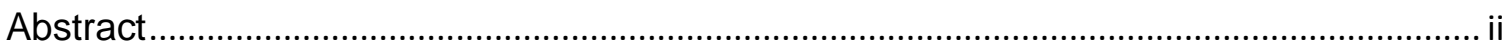

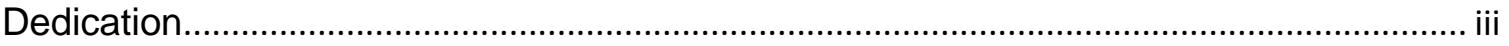

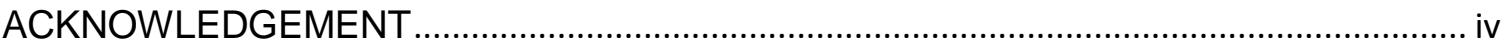

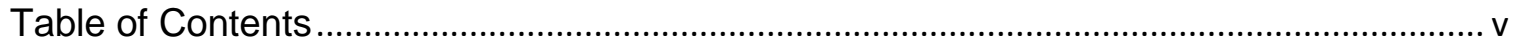

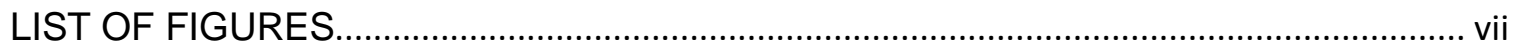

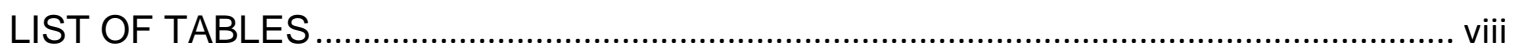

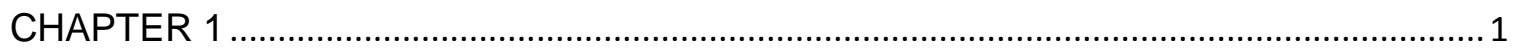

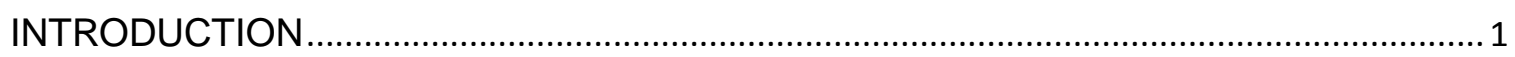

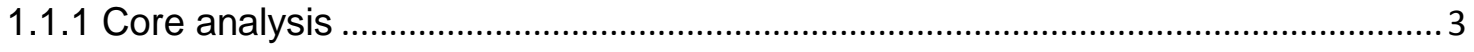

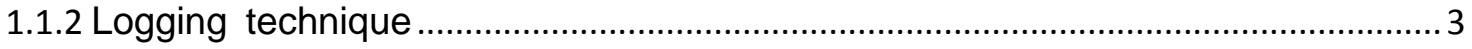

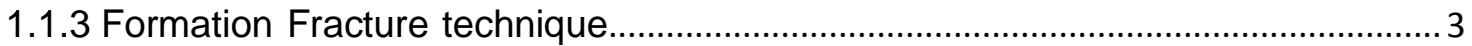

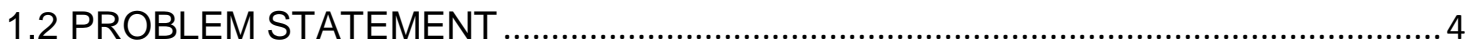

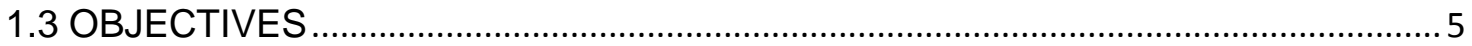

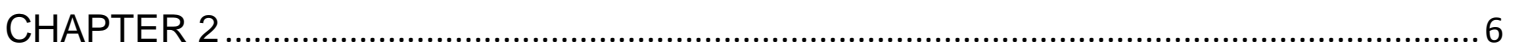

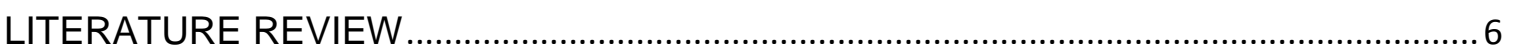

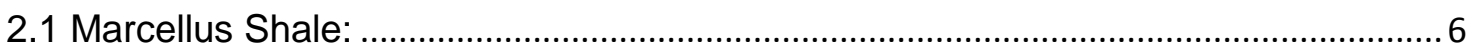

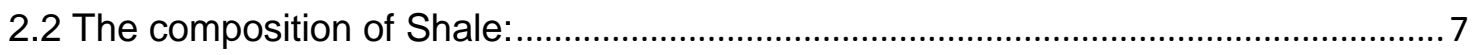

2.3 Contemporary Stress Field: .................................................................................... 7

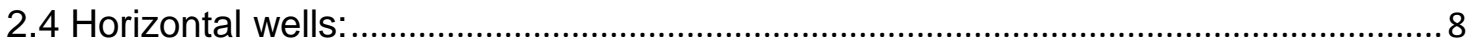

2.5 Stresses:

2.5.1 In-situ stress:

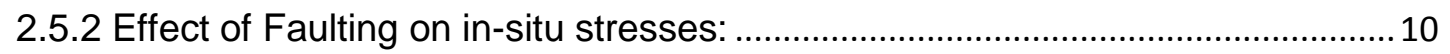

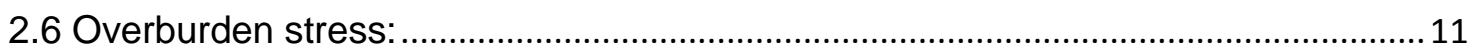

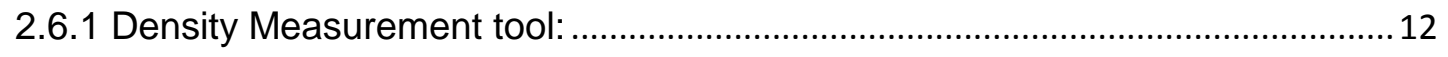

2.6.2 Well Logging Stress measurement: .................................................................. 13

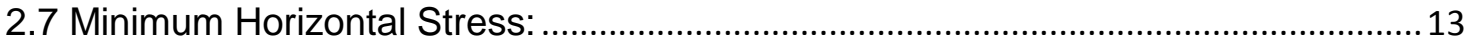

2.7.1 Application of Minimum Horizontal Stress:........................................................ 14

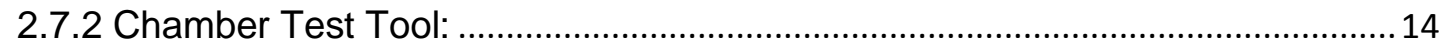

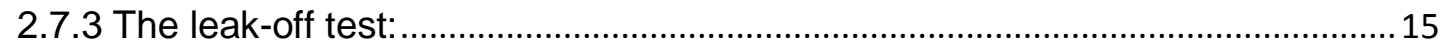




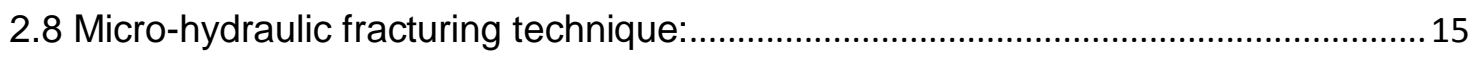

2.8.1 Stress Measurements by Hydraulic fracturing: :.................................................... 16

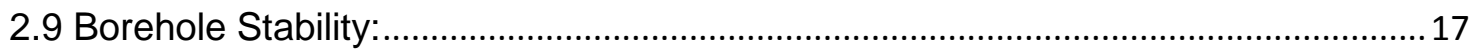

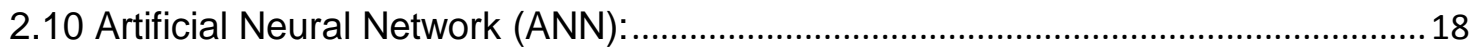

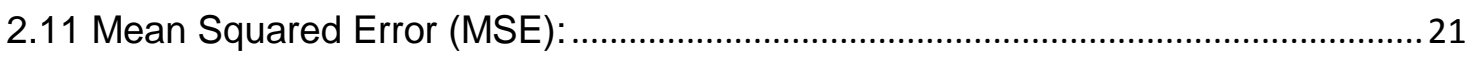

2.12 Neural Networks used for GeoMechanics Rocks and Stresses: - ..........................22

2.13 Accurate In-Situ Stress Measurement During Drilling Operations: - ..........................23

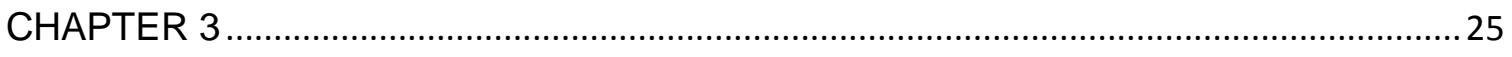

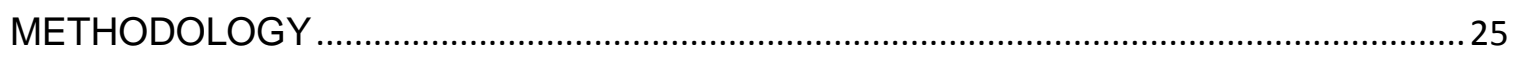

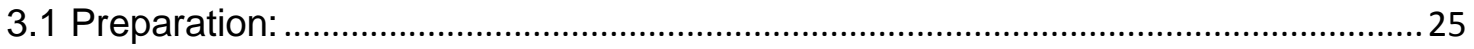

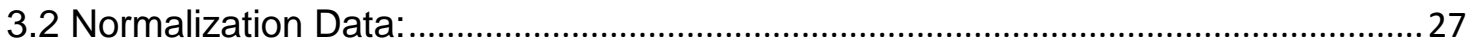

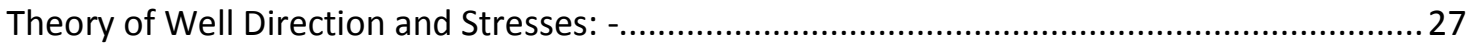

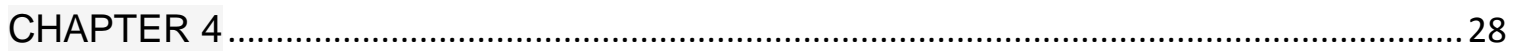

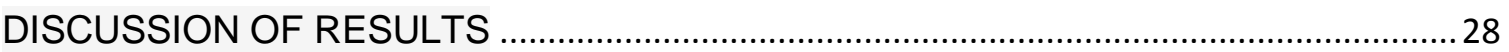

4.1 Vertical Well Section (VWS) - Horizontal Stress (HS) ...........................................28

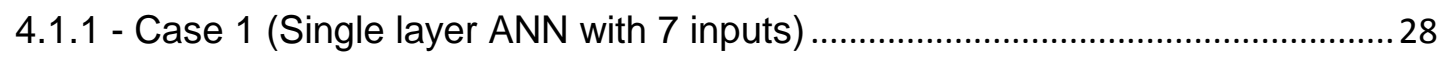

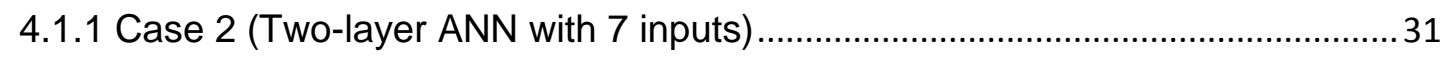

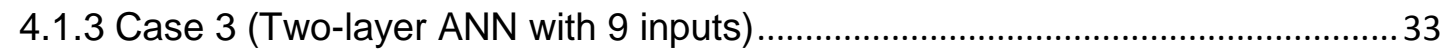

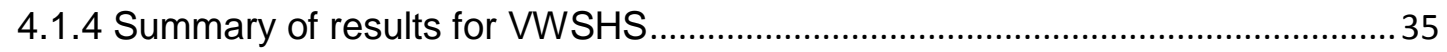

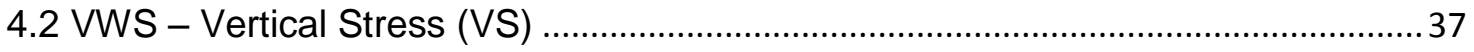

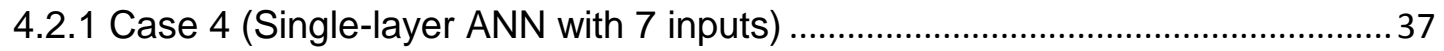

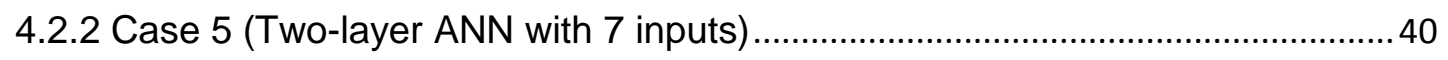

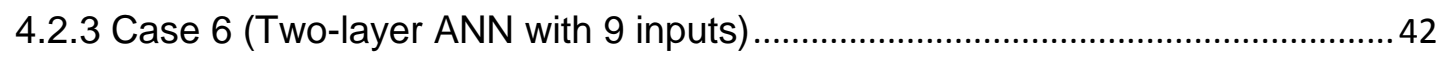

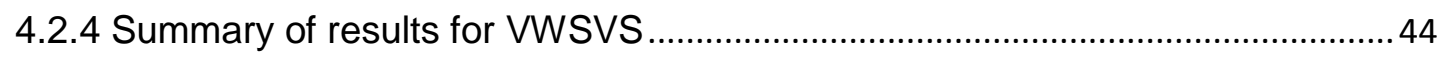

4.3 Horizontal Well Section (HWS) - Horizontal Stress (HS) ....................................... 46

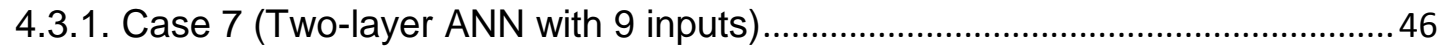

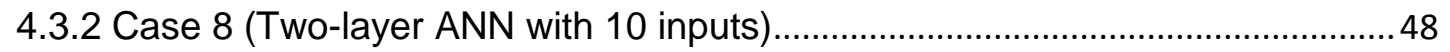

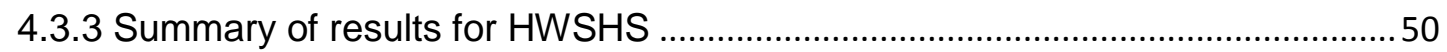

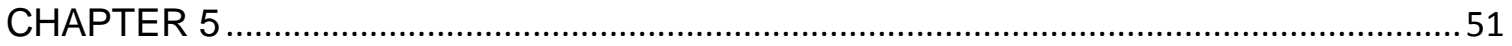

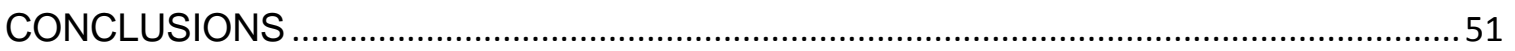

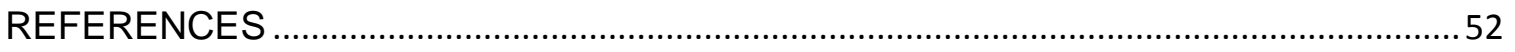




\section{LIST OF FIGURES}

Figure 1: MARCELLUS SHALE LoCATIONS (MARCELLUS SHALE MAP, 2017) .................................. 6

FIGURE 2: SAMPLES ANALYSIS OF ROCKS (WVU NATIONAL RESEARCH CENTER ET AL, 2015) .............. 7

FIGURE 3: StRESS ORIENTATIONS IN THE APPALACHIAN BASIN (HEIDBACH ET AL., 2008)..................... 8

FIGURE 4: DRILLING AND STRESS DIRECTIONS (ART OF DIRECTIONAL DRILLING, 2015) ........................ 8

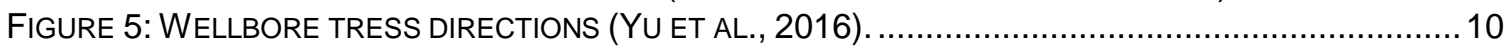

FIGURE 6: FAULT TYPES AND ASSOCIATED STRESSES (FJAER ET AL., 2008). ...................................11

FIGURE 7: DENSITY WIRELINE MEASUREMENT TOOL WITH THREE DETECTORS (SCHLUMBERGER, 2001) 12

FIGURE 8: WIRELINE CLOSED CHAMBER TEST TOOL (DESROCHES AND KURKJIAN, 1999). ...................14

FIGURE 9: DOWN-HOLE PRESSURE PROFILE DURING MICRO-FRACTURING TEST (ECONOMIDES, ET AL,

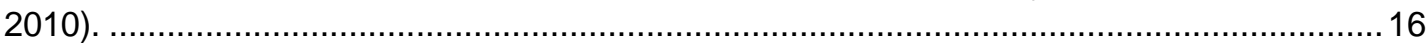

FIGURE 10: MOHR CIRCLE WITH FAILURE ENVELOPE (HOOKE, ET AL., 2005) ................................... 17

FIGURE 11: MINIMUM HORIZONTAL STRESS MAGNITUDE USED IN DECIDING SAFE MUD WEIGHT WINDOW

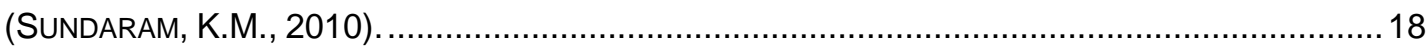

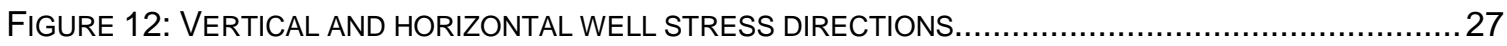

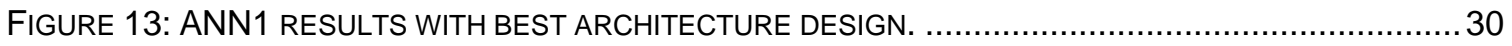

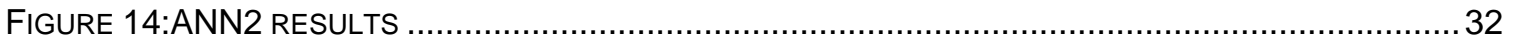

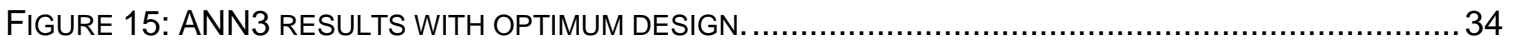

FIGURE 16: TWO-LAYER ANN PREDICTED AND MEASURED MINIMUM HORIZONTAL STRESS GRADIENT

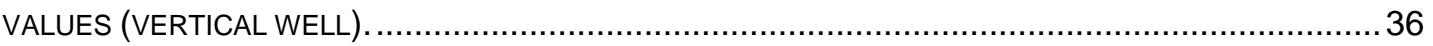

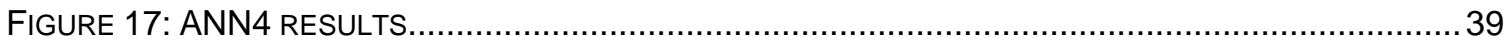

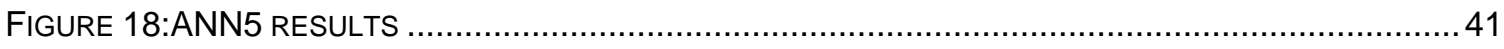

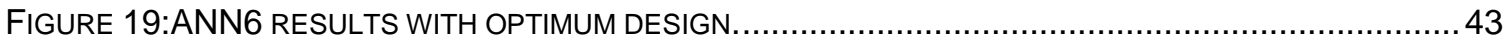

FIGURE 20: TWO-LAYER ANN PREDICTED AND MEASURED TOTAL VERTICAL STRESS GRADIENT VALUES

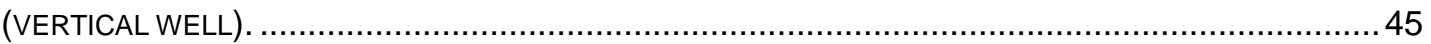

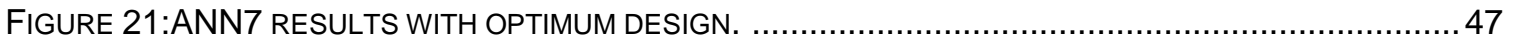

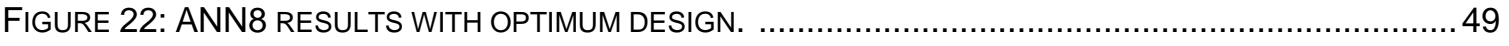

FIGURE 23: TWO LAYER ANN PREDICTED AND MEASURED MINIMUM HORIZONTAL STRESS GRADIENT

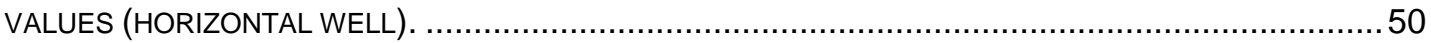




\section{LIST OF TABLES}

TABLE 1: Drilling Parameters InPUt Data of Vertical Well SECTION........................................ 25

TABLE 2: StRESSES PARAMETERS TARget DATA OF VerTICAL WELL DATA SECTION ........................26

TABLE 3: DRILLING PARAMETERS INPUT DATA OF HORIZONTAL WELL SECTION .....................................26

TABLE 4: StRess PARAMETERS TARGet DAtA OF HoRIZONTAL WELL SECTION................................. 26

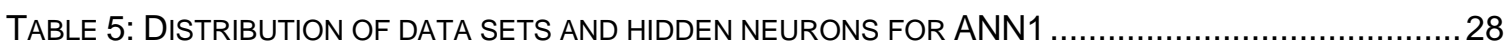

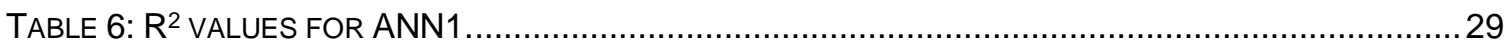

TABLE 7: COMPARISON OF MEASURED AND PREDICTED VALUES OF MINIMUM, MAXIMUM, AND AVERAGE

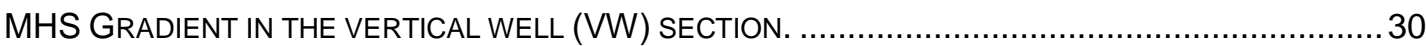

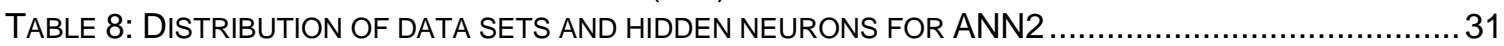

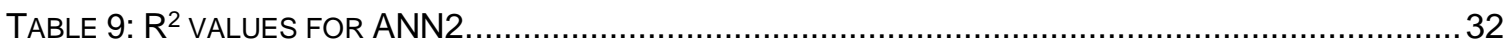

TABLE 10: COMPARISON OF MEASURED AND PREDICTED VALUES OF MINIMUM, MAXIMUM, AND AVERAGE

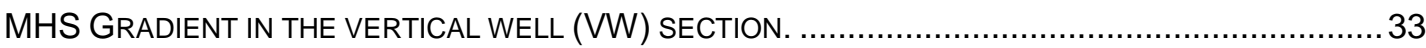

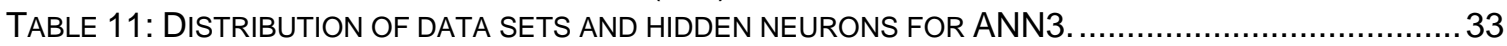

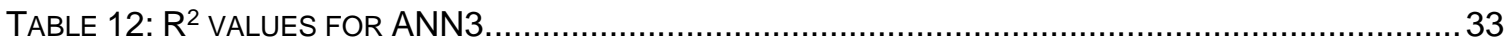

TABLE 13: COMPARISON OF MEASURED AND PREDICTED VALUES OF MINIMUM, MAXIMUM, AND AVERAGE

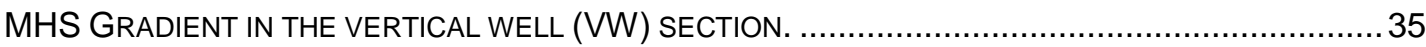

TABLE 14: COMPARISON OF MEASURED AND ANN PREDICTED HORIZONTAL STRESS VALUES IN VERTICAL

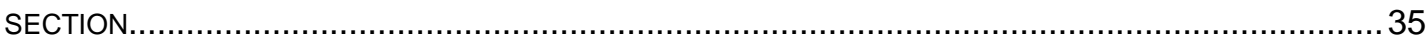

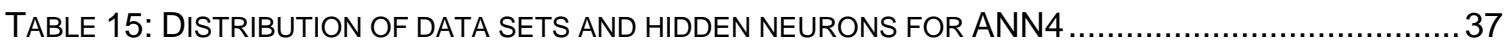

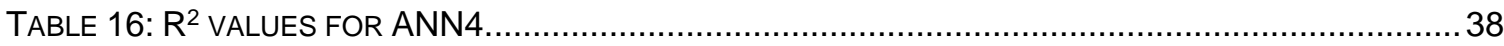

TABLE 17: COMPARISON OF MEASURED AND PREDICTED VALUES OF MINIMUM, MAXIMUM, AND AVERAGE

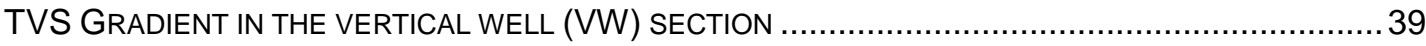

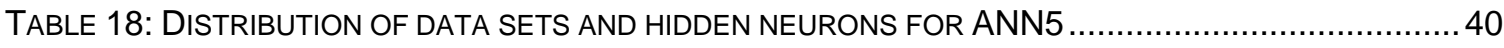

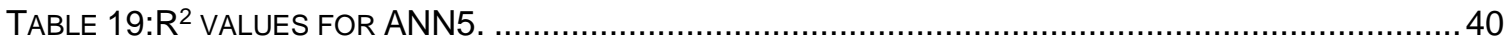

TABLE 20: COMPARISON OF MEASURED AND PREDICTED VALUES OF MINIMUM, MAXIMUM, AND AVERAGE

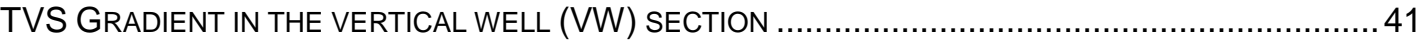

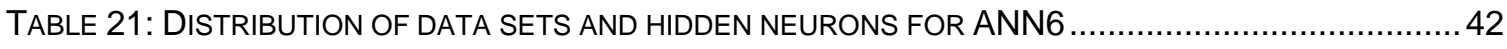

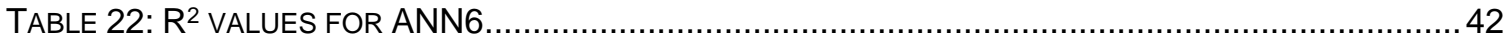

TABLE 23: COMPARISON OF MEASURED AND PREDICTED VALUES OF MINIMUM, MAXIMUM, AND AVERAGE

TVS GRADIENT IN THE VERTICAL WELL (VW) SECTION. ...................................................... 43

TABLE 24: COMPARISON OF MEASURED AND ANN PREDICTED VERTICAL STRESS VALUES IN VERTICAL

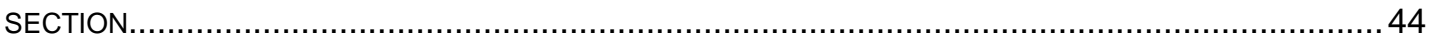

TABLE 25: DISTRIBUTION OF DATA SETS AND HIDDEN NEURONS FOR ANN7 . ................................. 46

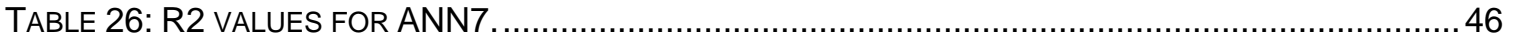

TABLE 27: COMPARISON OF MEASURED AND PREDICTED VALUES OF MINIMUM, MAXIMUM, AND AVERAGE

MHS GRADIENT IN THE HORIZONTAL WELL (HW) SECTION................................................. 47

TABLE 28: DISTRIBUTION OF DATA SETS AND HIDDEN NEURONS FOR ANN8 ................................. 48

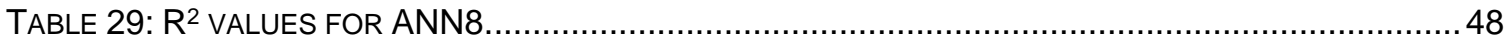

TABLE 30: COMPARISON OF MEASURED AND PREDICTED VALUES OF MINIMUM, MAXIMUM, AND AVERAGE MHS GRADIENT IN THE HORIZONTAL WELL (HW (SECTION. ................................................... 49

TABLE 31: COMPARISON OF MEASURED AND ANN PREDICTED HORIZONTAL STRESS VALUES IN HORIZONTAL SECTION. 


\section{LIST OF SYMBOLS / NOMENCLATURE}

$\mathrm{d}=$ Depth of the formation ( $\mathrm{ft}$ )

$g=$ Gravitational constant (32.175 ft/s2)

$\mathrm{h}=$ Vertical height of the formation (ft)

$\rho=$ Bulk density of the formation (lb. /ft3).

$\sigma \mathrm{v}=$ Vertical stress, psi.

$E=$ Young's modulus, psi.

$\mathrm{V}=$ Poison's ratio .

$u_{s}=$ Shear waves

$u_{c}=$ Compression waves

$\sigma \mathrm{h}, \min =$ Minimum horizontal stress. $\mathrm{psi}$

$\alpha \mathrm{h}=$ Vertical Biot's coefficient .

$\mathrm{Pp}=$ Pore pressure, $\mathrm{psi}$.

$\alpha=$ Biot Poro-elastic constant

$\varepsilon \mathrm{H}, \mathrm{h}=$ Horizontal and vertical strain, psi

PISIP = Instantaneous shut-in pressure, psi.

$\mathrm{m}=$ slope.

$\sigma 1,2,3=$ The three principle stresses, psi

Ppd $=$ Break down pressure, psi .

$\mathrm{T}=$ Tensile strength, psi.

TVS-VW= Total Vertical Stress Gradient Vertical Well (psi/ft).

MHS-VW= Minimum Horizontal Stress Gradient Vertical Well (psi/ft)

MHS-HW= Minimum Horizontal Stress Gradient Horizontal Well (psi/ft)

$\mathrm{ANN}=$ Artificial Neural Networks.

$\mathrm{MSE}=$ Mean Squared Error.

$\mathrm{X}_{\text {new }}=$ Normalized value.

$\mathrm{X}=$ Original value.

$\mathrm{X}_{\min }=$ Minimum value.

$\mathrm{X}_{\max }=$ Maximum value. 


\section{CHAPTER 1 \\ INTRODUCTION}

By the Geological definition, stress is stated as the force per unit area placed on a body mass, namely the rock. Stresses have different types that act on any material or mass. Confining stresses impact the mass by pushing inwards from all sides. If these stresses are all equal, then they could make rocks become compressed but will not deform its shape, and will cause the rock to stay in place and not move. Compression stress is referred to the stress that squeezes rocks together causing them to fold or fracture. On the contrary, tension stresses can break rocks into parts or lengths primarily at the rock's divergent plate boundaries. Shear stresses are impact forces acting parallel to each other in opposite directions.

In reservoir geomechanics, it is important to have a sufficient description of the in-situ stress magnitudes and orientations and indicate how they may evolve with the development of a stress field. These stress changes affect most reservoirs but have the greatest influence on reservoirs with fluids and stresses flowing through fractures, either natural or induced. But, towards developmental decisions in exploiting unconventional resources, stress deviation of hydraulic fracturing are very important aspects in geological evaluations and in geomechanics.

The distribution and magnitude of in situ stresses affect the dimensioning of the orientation of underground excavations, the excavation sequence, geometry, and shape. The knowledge of the in-situ stress state in the earth's crust is critical in solving many problems dealing with rocks in civil, mining, and petroleum engineering, energy development, geology, and geophysics. In engineering, in situ stresses are the main factors to be considered in the excavation design and the crucial stability decisions for the underground construction. 
Also, the vertical stress (SV) is regarded as one of the primary principal stresses; the other two principal stresses are the minimum horizontal stress (sh) and the maximum horizontal stress $(\mathrm{sH})$. The vertical stress (SV) is considered to be the overburden stress in the earth's subsurface that extends beyond the overlying mass of rock by gravitational loading. The maximum horizontal stress (sH) magnitude is important, because it impacts the mass when the wellbore stability and the likelihood of creating complex non-planar hydraulic fractures occurs. The minimum horizontal stress (sh) can be determined directly from injection tests where fluid is pumped into a formation. When a small fracture is created, the well is shut in, and the pressure (minimum Horizontal stress point) at which the fracture closes is measured.

It is important to determine the stresses because it impacts the followings:

- Hydraulic propagation in vertical and deviated wells.

- Multi-stage hydraulic fracturing.

- Alteration of formation properties with production.

- Impact of fractures and faults on well productivity.

- Simulating of low permeability formations for production improvement.

- Shear velocity anisotropy determination.

- Wellbore stability changes during drilling operations.

The different methods exist to measure the magnitude and direction of the horizontal in-situ stresses and they are categorized in three main groups as (Carnegie et al., (2002)):

1. Core analysis.

2. Logging technique.

3. Formation fracture technique. 


\subsubsection{Core analysis}

This method involves performing of different strain experiments with core samples from the region of interest. The results obtained are then analyzed and interpreted to estimate the magnitude and direction of the in-situ stresses.

\subsubsection{Logging technique}

This technique is based on the interpretation of stress through a model that uses borehole breakout measurements or other relationships that exist close to the face of the wellbore. An ideal way in determining the stresses is using the Poisson's ratio obtained from sonic velocities. The relationship between the rock properties and stresses is semi- empirical. To find the absolute stress values, data from more accurate methods like the micro-fracturing technique are used for calibration which is done in conventional and unconventional reservoirs.

\subsubsection{Formation Fracture technique}

It is known as a downhole fracturing method and consists of tests like Leakoff tests, Micro-Fracturing, Extended leak-off tests are some popular examples. The formation is pressurized until it fractures and measurements taken at different stages are used to compute and estimate the stresses. 


\subsection{PROBLEM STATEMENT}

Logging in a horizontal drilling can be a problem. It is a time-consuming and expensive and it is also very challenging to perform due to the geometry of the well. Problems arise with greater depths, higher angles, and lengthier horizontal sections. Also, running logging tools into the hole on wireline becomes difficult when hole angles get deflections. When a hole is diverted from the vertical, the stresses acting on the wellbore wall differ in a way where the difference between the maximum and minimum stress acting on the well becomes greater. It is important to know the stress values in a well in order to modify initial design during drilling operations that can eliminate problems arising from unwanted wellbore or equipment failures. 


\subsection{OBJECTIVES}

The main objective of this study was to determine the principal stresses of Marcellus Shale formations using the data recorded during daily drilling operation. Specifically, the total vertical stress and minimum horizontal stress gradients were considered for this investigation.

The work consisted of data gathered in a horizontally drilled shale well located in Monongalia County, West Virginia. Relevant data from drilling were analyzed and used to estimate stresses using a neural network program. Tasks to perform for reaching the objective can be summarized with the following steps:

1. Acquire field data regarding drilling parameters and stress measurements.

2. Sort drilling data to determine vertical and horizontal parts.

3. Determine and evaluate measured stresses for the Marcellus shale

4. Design different neural networks to predict stresses using data for vertical section of the well.

5. Design different neural networks to predict stresses using data for horizontal section of the well

6. Determine the importance of input parameters in predictions.

7. Run neural networks to determine the optimum model with best results. 


\section{CHAPTER 2}

\section{LITERATURE REVIEW}

\subsection{Marcellus Shale:}

The Marcellus shale considers the most developed unconventional shale gas reservoirs in the USA with an estimated 84.5 trillion cubic feet in natural gas reserves in Pennsylvania and West Virginia Area. As Figure 1 shows below, The Marcellus shale is comparatively shallow in New York and is deepest in Central Pennsylvania reaching a maximum depth of over 9000 feet with the top of the Marcellus shale at -7129 feet measured depth. The Marcellus shale is 106 feet thick and contains an organic-rich zone 23 feet thick known as the lower Marcellus by Log Analysis. The Marcellus shale thickens to the east and has a thickness of 50-150 feet in Harrison County West Virginia. (Marcellus Center for Outreach and Research, 2008).

Marcellus shale has ranged from 0 feet at the surface of central Pennsylvania to 9000 feet in parts of southwestern and northeastern Pennsylvania. The net thickness of organic rich section has reached from less than 10 feet in western Pennsylvania along the Ohio border to over 250 feet in northeastern Pennsylvania (PADCNR,2017). West Virginia 21,840 billion cubic feet total natural gas 2015(U.S. Energy Information Administration, 2016)

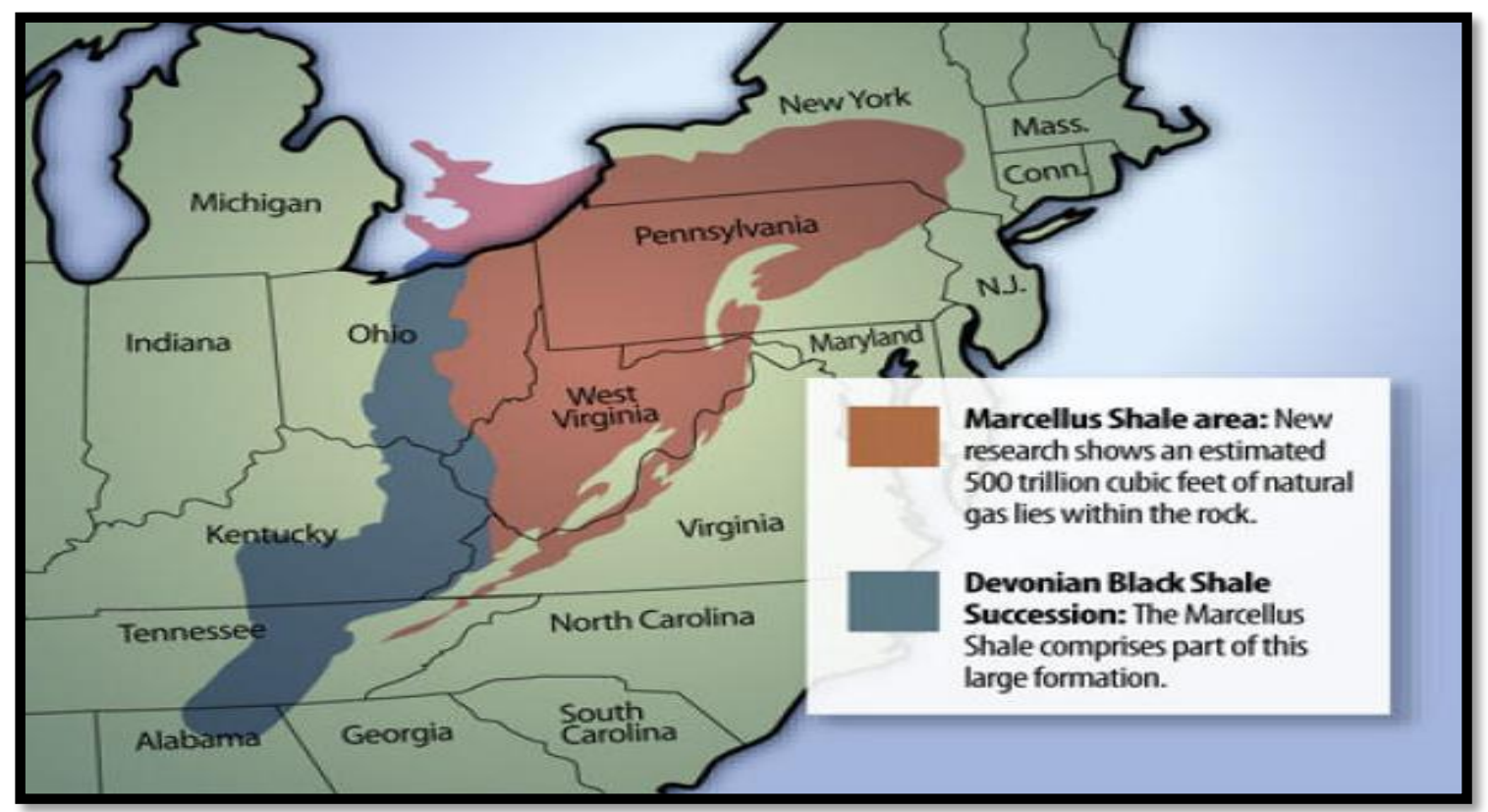

Figure 1: Marcellus Shale Locations (Marcellus Shale Map, 2017). 


\subsection{The composition of Shale:}

Shale has composed mainly two of clay size and grain size`s of rock. The components of tiny grains are illite, kaolinite, and smectite. The clays include quartz, chert, and feldspar. Figure 2 shows a core samples of shale. Some constituents include organic particles like carbonate minerals, iron oxide minerals, sulfide minerals, and heavy mineral grains (Boch et al, 2002)

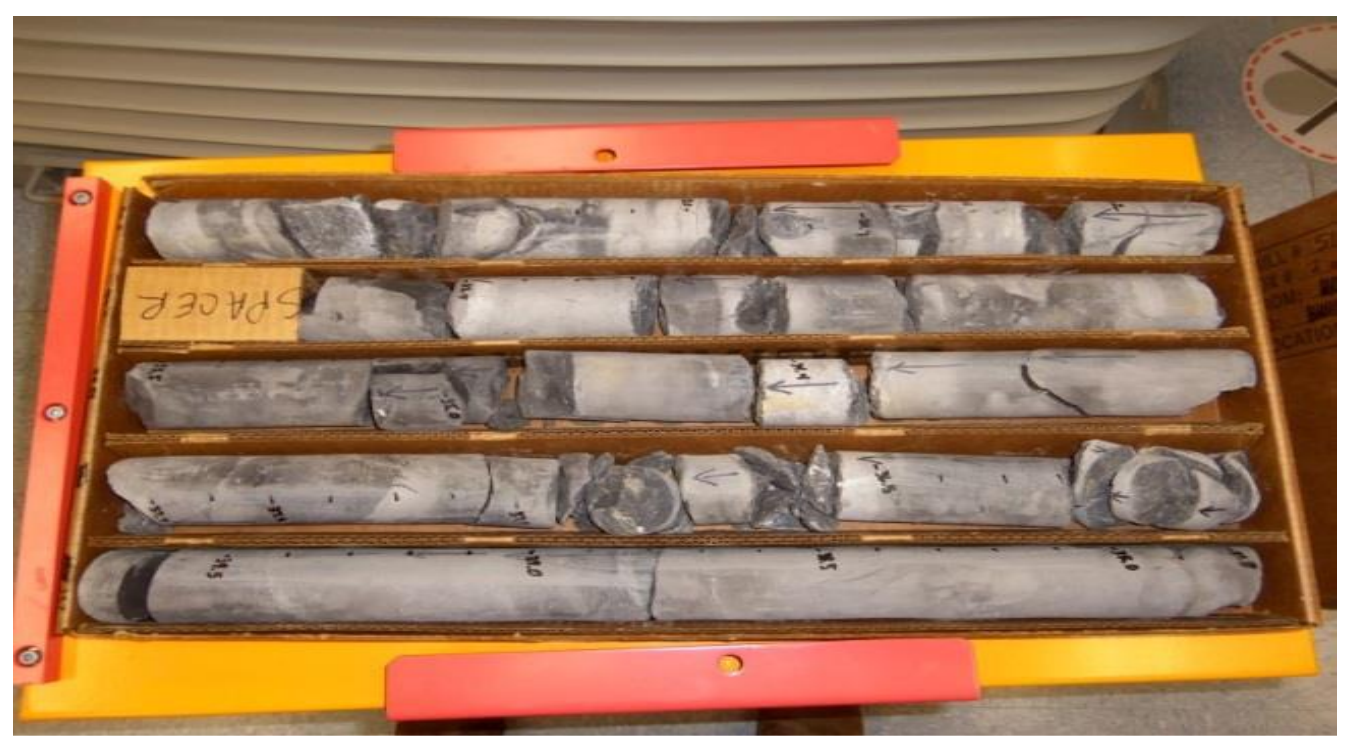

Figure 2: Samples analysis of Rocks (WVU National Research Center et al, 2015)

\subsection{Contemporary Stress Field:}

Contemporary stress orientations have been plotted in the World Stress Map Project and shown in Figure 3 below (Heidbach et al., 2008). The original sources were estimated starting from 1972 through 1990 before the large-scale performance of horizontal drilling, hydraulic fracture treatment, and formation image logging tools have begun in the late 2000's (Beard, 2011; Zagorski et. al, 2012). Since production from the Marcellus Shale started in the region, knowledge of stress data became important in areas where data control was low such as in northeastern West Virginia and southwestern Pennsylvania. 


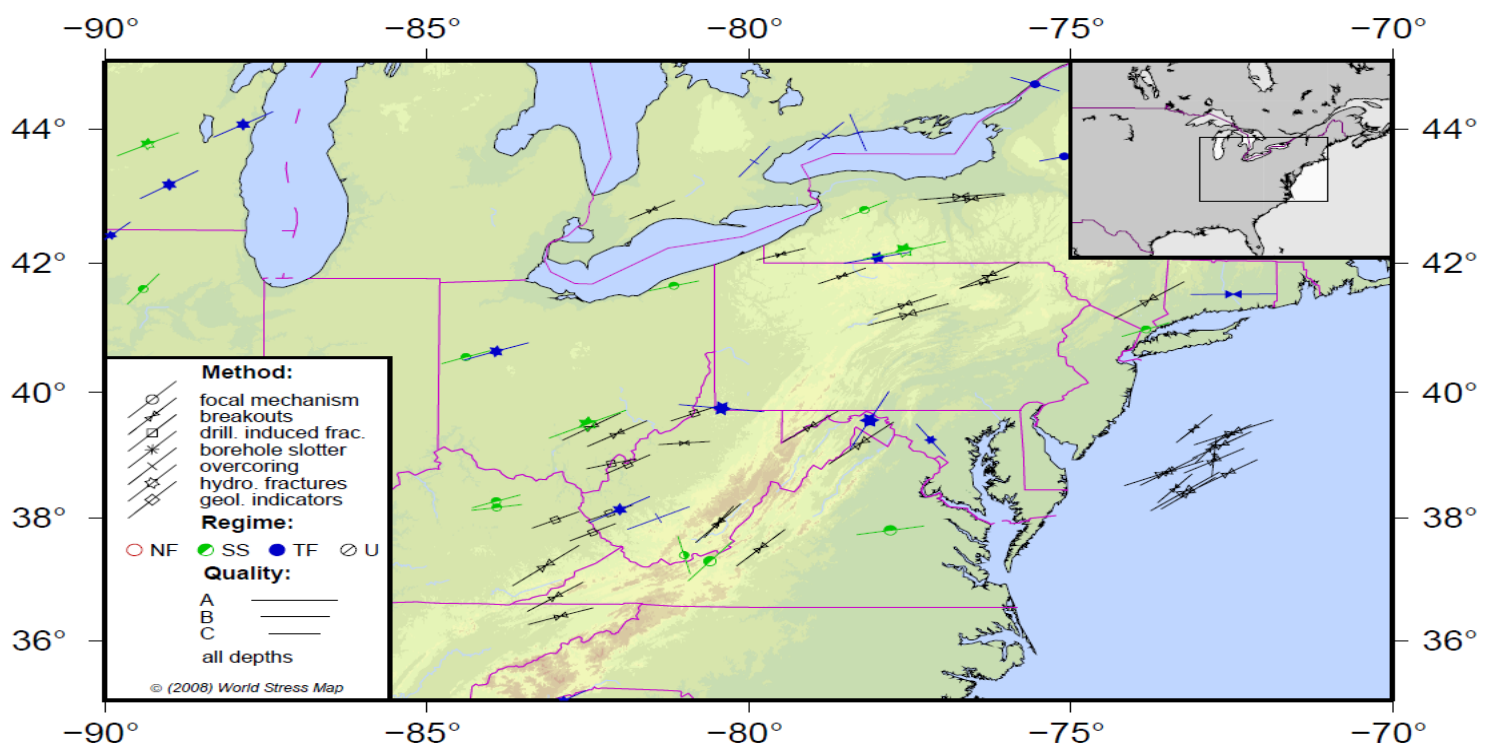

Figure 3: Stress orientations in the Appalachian basin (Heidbach et al., 2008).

\subsection{Horizontal wells:}

Horizontal wells provide a drilling process through vertical sections and then horizontally into the formation. The drilling curves up starting with a whipstocks or other means and becomes horizontal with a short, medium or long turn angle. Turn angle sections have to be drilled in open holes. Depending upon the drilling situation, motor assemblies and some rotating assemblies are selected in a drilling processes. Figure 4 shows drilling and stress directions in a well (Short,1993).

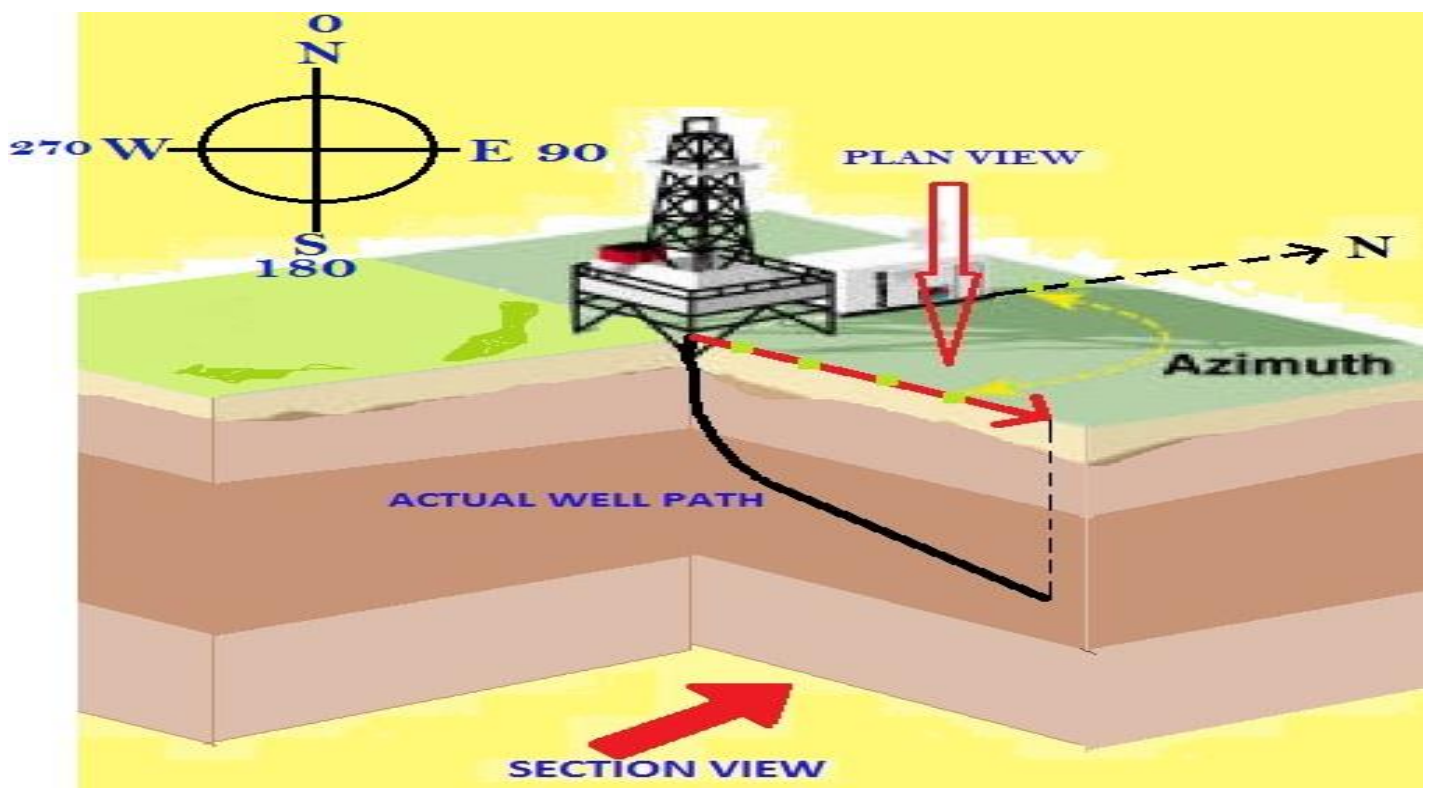

Figure 4: Drilling and stress directions (Art of Directional Drilling, 2015). 


\subsection{Stresses:}

Measured profiles of stresses play an important role for the design of hydraulic fracturing and the estimation of wellbore stability. A successful measurement method is the use of logs that have become the industry standard for determining the stress profile in the reservoir. Also, it is important to know the general magnitude of stress and in particular as it represents the rock mechanics. Stress is a reaction of internal resistance in a body that is experiencing external forces. Stress is not dependent on the size and shape of a body only, but it is dependent on its orientation as well (Aadnøy and Looyeh, 2011).

Stress is defined as the ratio of force to cross-sectional unit area as shown in equation (1) below,

$$
\sigma=\frac{\text { Force }}{\text { Area }}=\frac{F}{A}
$$

Pascal ( $\mathrm{Pa}$ or $\left.\mathrm{N} / \mathrm{m}^{2}\right)$ is the SI unit of stress, however, pounds per square inch (psi) is commonly in the oil and gas industry as unit.

\subsubsection{In-situ stress:}

The in-situ stress, also termed as far-field stress is the state of the stress of the rock formation in its original, relaxed and undisturbed position before any drilling activity is done. These stresses generally are compressive in nature and consist of three in-situ principal stresses, mutually perpendicular to one another and present at any point in the subsurface, as shown in Figure 5. The principal stresses are known as those normal components of stress that act on planes and have shear stress components with zero magnitudes. Figure 5 shows the stress as a tensor and can be explained as a point within the rock mass in term of magnitudes and orientation of three orthogonal principal stresses; overburden or vertical stress (SV), maximum horizontal stress (SH), and minimum horizontal stress (Sh). The measurement of magnitude is required so that the impacted rock body be determined to some degree (Aadnøy and Looyeh, 2011). 

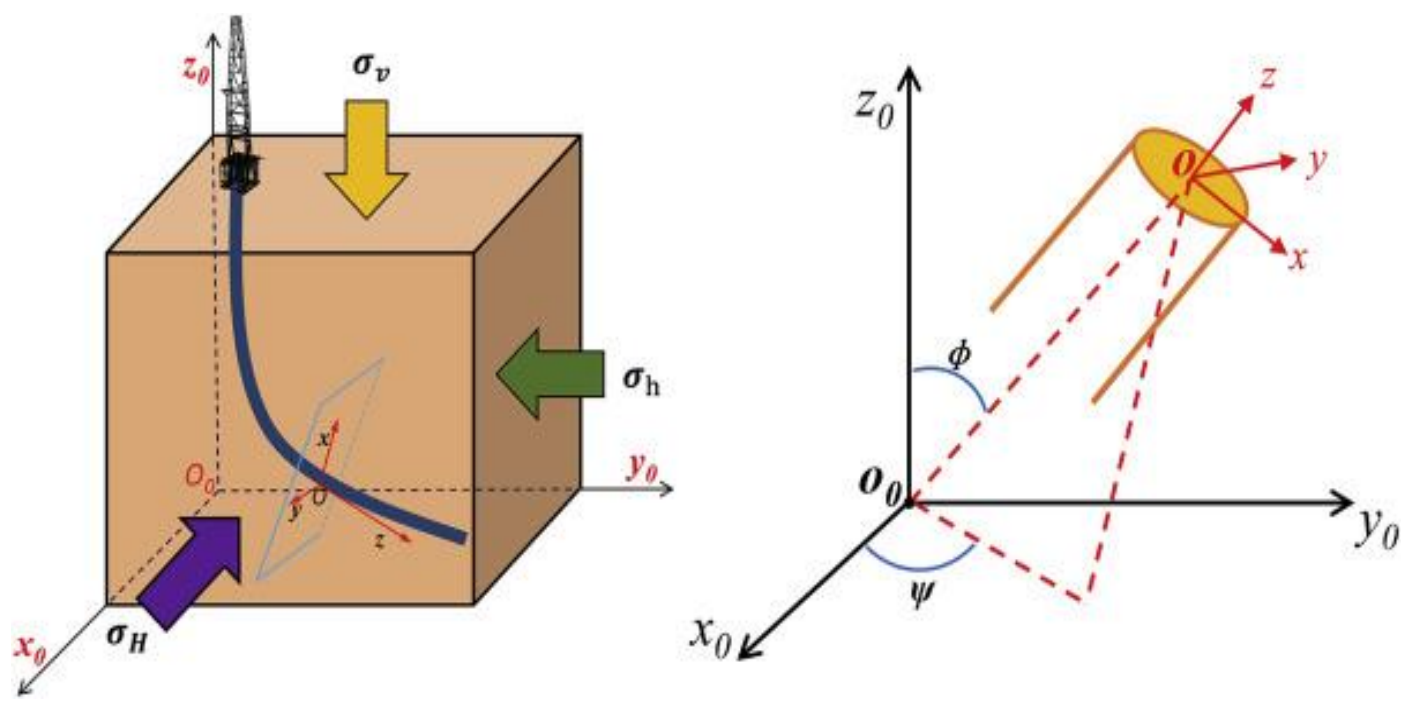

Figure 5: Wellbore tress directions (Yu et al., 2016).

\subsubsection{Effect of Faulting on in-situ stresses:}

The stresses have two types in a body. The stress that acts perpendicular to the plane is named normal stress, $\sigma$, and another stress which acts parallel to the plane.is called shear stress, $\mathrm{T}$.

It is expected that the overburden stress is the largest in magnitude while the minimum and maximum horizontal stresses are equal in the basin that is comfortable tectonically. However, the existence of faulting affects the magnitude of the in-situ stresses. Stresses in a region due to normal faulting, reverse faulting and strike-slip faulting are categorized below, (Aadnoy and Hansen, 2005) and also shown in Figure 6;

Normal fault stress state: $\sigma v>\sigma H>\sigma h$

Reverse fault stress state: $\sigma H>\sigma h>\sigma v$

Strike-slip fault stress state: $\sigma H>\sigma v>\sigma h$

Three shapes are illustrated in the faulting scenarios. They are provided that the directions of one of the principal stresses is vertical. A normal fault occurs when the largest of the principal stresses, $\sigma 1$ is vertical, and the dip is greater than $45^{\circ}$, commonly about $60^{\circ}$. 
Thrust fault happens when the least principal stress, $\sigma 3$ is vertical; the hanging wall moves upward with the dip is smaller than 45 , usually about $30^{\circ}$. When the intermediate principal stress, $\sigma 2$ is vertical, and failure planes are dominant and vertical, strike-slip fault occurs (Fjaer et al., 2008).

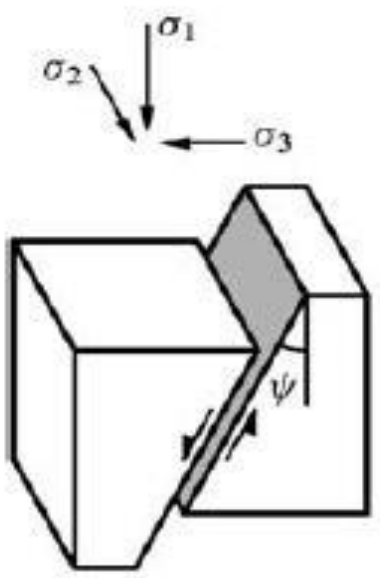

$\sigma_{1}$ vertical

Normal fault
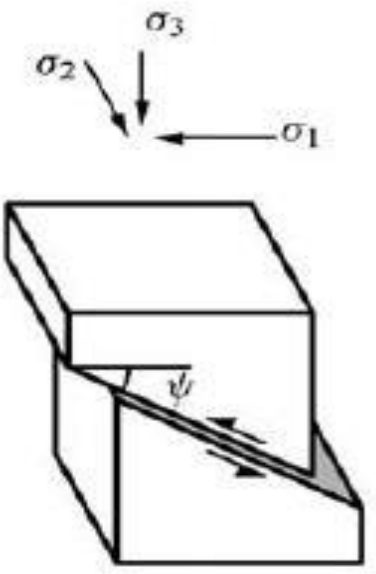

$\sigma_{3}$ vertical

Thrust fault
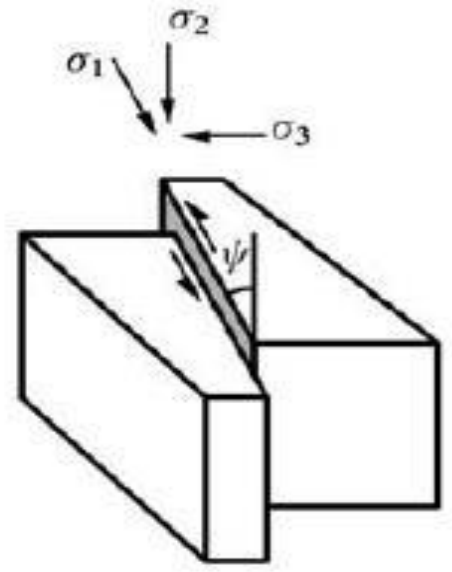

$\sigma_{2}$ vertical

Strike-slip fault

Figure 6: Fault types and associated stresses (Fjaer et al., 2008).

\subsection{Overburden stress:}

The overburden stress is also named the vertical stress and it is a result of the weight of overlying rock matrices and the fluids in the rock pores. The vertical stress may not consider a principal stress because of the topography which could not be horizontal or due to some of other geological processes, faults and tectonic stresses (Thorsen, 2011). As an example, geological vertical stress effects like magma considers sources of the overburden stress. Due to Poisson's ratio effect, the weight is extended by the vertical stress component and usually has the orientation to extend and expand the rocks underneath in the horizontal or lateral direction (Aadnøy and Looyeh, 2011).

The overburden stress can be calculated by Equation (2):

$$
\sigma v(Z 0)=\int_{0}^{Z 0} \rho b g d z
$$




\subsubsection{Density Measurement tool:}

The density log is used to determine overburden stress. Density tools provide a measurement of formation density, photoelectric formation factor, and borehole diameter. The density data are also used to estimate porosity, lithology analysis for identification of minerals, rock mechanical properties estimation, and calculation of overburden stress. There are many different types of density measurement tools in the industry today. Some have three detectors with the third detector located close to the radiation source as a backscatter density measurement.

The density tools are active gamma ray tools that use the Compton scattering of gamma rays to measure or determine the electron density of the formation. As shown in Figure 7 below, a radioactive source produces and emits medium energy gamma rays into the formations. The density tool sends an erroneous formation density value when running in the borehole with high barite content in the drilling mud. This is because barite has an electron density of 267 barns/electrons compared to values less than 6 barns/electron for most common minerals (Schlumberger, 1985). Also, a mud cake contains 60 percent barite by weight can create a bulk density of $2.5 \mathrm{~g} / \mathrm{cc}$, but its effect could be the same as that of a barite free mud cake with a density of $3.5 \mathrm{~g} / \mathrm{cc}$ (Wahl, et al., 1964). Although some effects cancel each other, a certain amount of correction is needed for borehole and heavy mud weight due to the amount of barite (Nieto, et al., 2005)

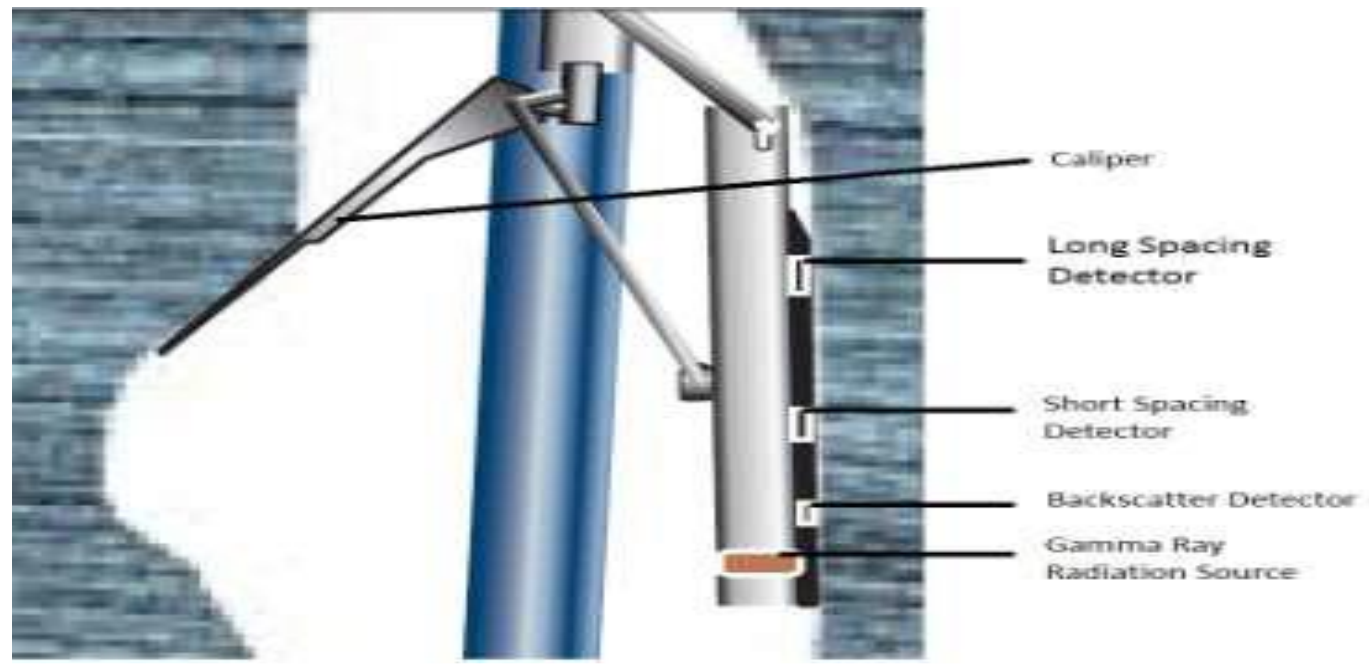

Figure 7: Density wireline measurement tool with three detectors (Schlumberger, 2001) 


\subsubsection{Well Logging Stress measurement:}

Well logging is used to estimate rocks' geomechanical properties. The formation bulk density is measured to determine the overburden stress (vertical stress). Formation bulk density is one of the properties that can be determined using the radioactive logging tool (Gamma-ray). However, sonic logs are applied to estimate other geomechanical properties such as Poison's ratio equation (3) and Young's modulus equation (4). The sonic waves propagate through the rocks which cause rocks deformation, this deformation affects both compression and shear waves. Thus, the tools of modern sonic logging have enough spacing between wave transmitting and receiving points for better determination of velocities' slowness (Valk, et al., 1995). Poison's ratio and Young's modulus are calculated from sonic logs using the following formulas.

$$
\begin{gathered}
V=\frac{0.5\left(\frac{u_{c}}{u_{s}}\right)^{2}-1}{\left(\frac{u_{c}}{u_{s}}\right)^{2}-1} \\
E=\rho u_{s}{ }^{2}\left[\frac{3 u_{c}^{2}-4 u_{s}^{2}}{u_{c}{ }^{2}-u_{s}{ }^{2}}\right]
\end{gathered}
$$

\subsection{Minimum Horizontal Stress:}

Minimum horizontal stress $(\sigma h)$ considers one of three principal stresses which can be measured and technically determined. $\sigma h$ is typically directly measured from smaller or larger rock formation fracturing tests or predicted from logging data (Zoback, 2007). The minimum horizontal stresses can be calculated by equation (5):

$$
\sigma h-\alpha h P p=\frac{v}{1-v}(\sigma v-\alpha P p)+\frac{E}{1-v^{2}} \varepsilon h+\frac{E v}{1-v^{2}} \varepsilon H
$$




\subsubsection{Application of Minimum Horizontal Stress:}

Minimum horizontal stress is required for planning borehole stability, hydraulic fracturing for gas production, estimation of wellbore collapse and sand production due to perforations (Sinha, et al., 2008).

\subsubsection{Chamber Test Tool:}

Chamber test tool is performed by downhole injection using wireline. It is done in an open hole where two packers isolate fluid inflow. The tool consists of two inflatable packer elements that seal against the borehole wall to isolate an interval of the borehole. The length of the test interval (i.e. the distance between the two packers) ranges from 1 meter to 2.4 meters. The fracture is created by pumping wellbore fluid into the interval between the inflatable packer's elements as seen in Figure 8.

To estimate the magnitude of local stress, wireline closed chamber tool requires the creation of small fracture by using relatively low fluid injection rate and volume. Hence less net pressure occurs when a lower fracture is created, and the shut-in pressure is commonly used as a first order approximation of the stress (Warren and Smith 1985).

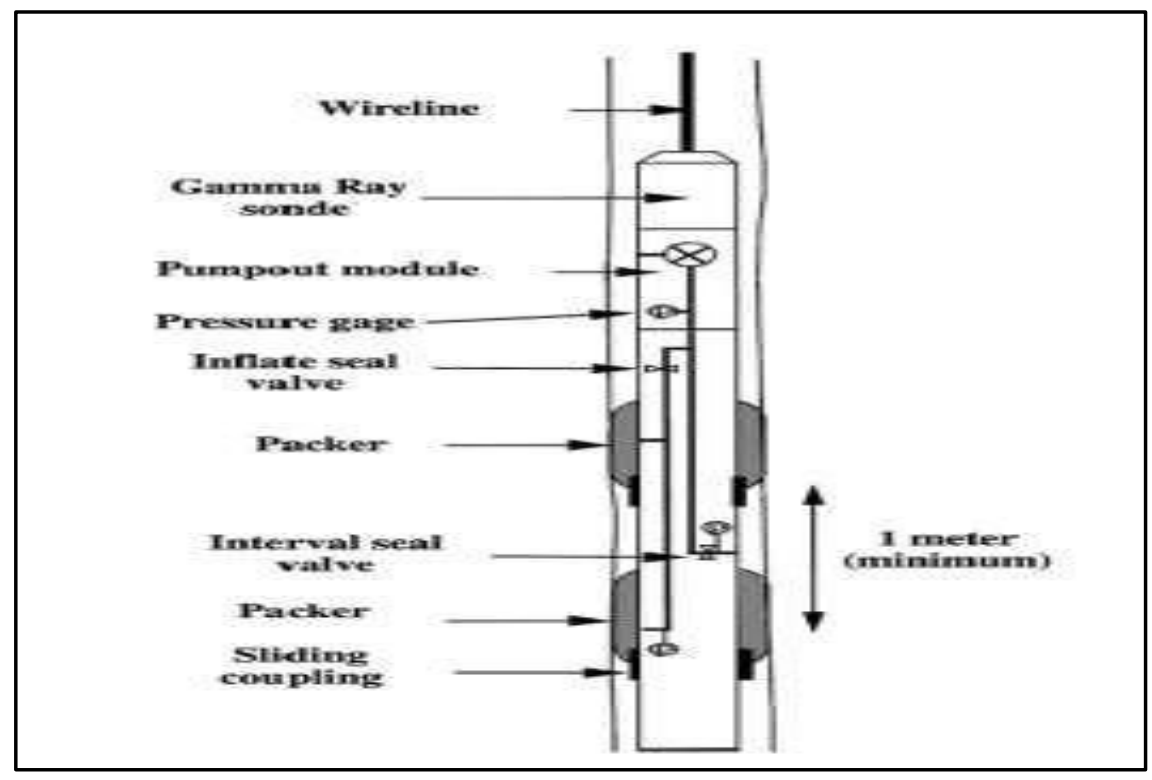

Figure 8: Wireline closed chamber test tool (Desroches and Kurkjian, 1999). 
Measurements are taken at different stages to compute or directly estimate the stresses. Tests such as leak-off test, hydraulic fracturing test, and microfracturing are some very familiar examples.

\subsubsection{The leak-off test:}

The leak-off test considers an upper bound of minimum horizontal stress. The most reliable estimate of minimum horizontal stress is obtained by injection tests including mini-frac (pump in/flow back, and pump in/shut in) tests [Teichrob et al., 2010].

\subsection{Micro-hydraulic fracturing technique:}

A mini-frac test makes a fracture perpendicular to the minimum principal stress (a strike-slip or normal stress regime). The pumps are suddenly stopped, and the pressure observed when the test was conducted with small treatment volume and low flow rate by pumping for certain time that causes the pressure to increase in an isolated section of the wellbore. After the fracture is created, the pumps are stopped, and the test interval is shut-in. The wellbore pressure initially declines, eventually slowing down and coming to an equilibrium pressure above hydrostatic. When the pressure declines, the newly created fracture closes. [Gronseth and Kry, 1983].

The initial shut-in pressure (ISIP) is considered to be equal to the minimum horizontal stress (equations (6) and (7));

$$
\begin{gathered}
I S I P=\sigma h_{\min } \\
B H P=m(\sqrt{\text { time })+} I S I P
\end{gathered}
$$

The Figure 9 below shows the pressure change with time during the typical micro-hydraulic fracturing test and also shows the ISIP after pumps shut-in. 


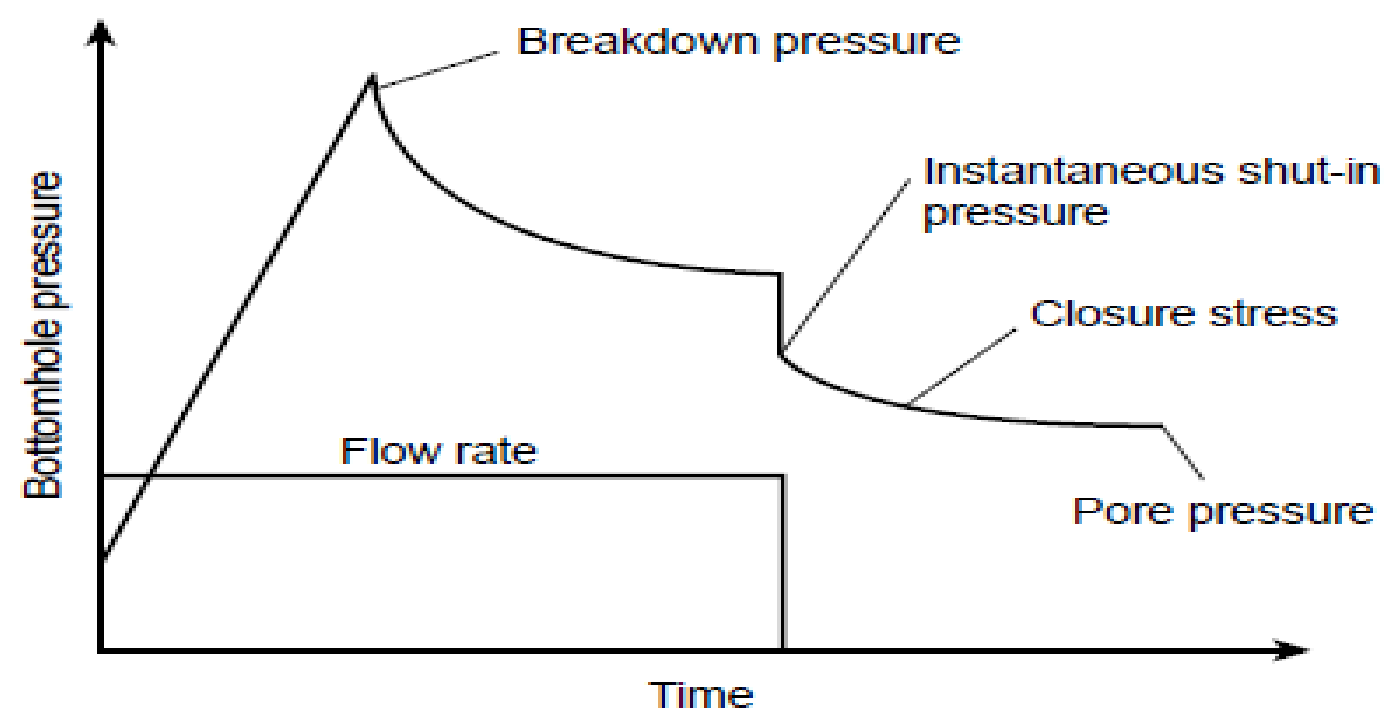

Figure 9: Down-hole pressure profile during micro-fracturing test (Economides, et al, 2010).

\subsubsection{Stress Measurements by Hydraulic fracturing:}

The rocks normally respond to changes in stress with different stages of deformation. This deformation can be elastic or permanent plastic deformation and it can end with the rock failure. The state of horizontal stresses is very important for the determination of the failure mechanism. For brittle rocks, the failure occurs catastrophically but if the rock is ductile, the failure occurs gradually (Cook, et al.,2007).

In order to determination horizontal stresses and related failure, one needs to recognize the relation between these stresses $(\sigma 1, \sigma 3)$ and normal stress $(\sigma n)$ and shear stress $(\zeta n)$ with arbitrary angle $\alpha$ in the direction of least principal stress $\sigma 3$ as shown in Figure 10 (Hubbert, et al., 1957)

The equations 8,9 , and 10 below show this relationship;

$$
\begin{gathered}
\sigma_{n}=\frac{\sigma_{1}+\sigma_{3}}{2}+\frac{\sigma_{1}-\sigma_{3}}{2} \cos 2 \propto \\
\tau=\frac{\sigma_{1}-\sigma_{3}}{2} \operatorname{Sin} 2 \propto \\
p_{p d}=3 \sigma_{3}-\sigma_{1}+T-P_{P}
\end{gathered}
$$




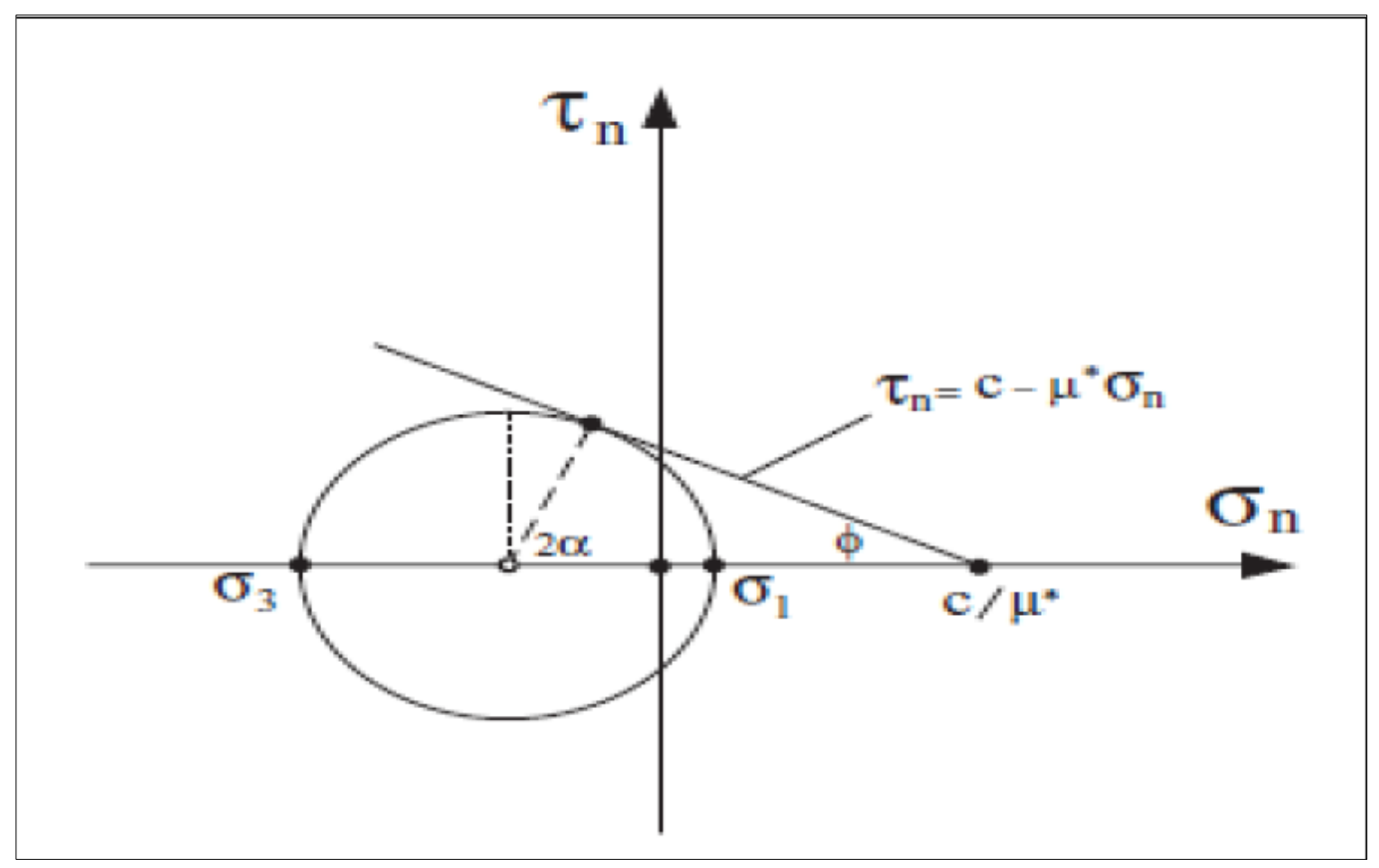

Figure 10: Mohr Circle with Failure envelope (Hooke, et al., 2005).

\subsection{Borehole Stability:}

A well understood geomechanical solution can suggest drilling directional wells at the right angles for the chosen trajectories. The necessary determinations needed are stress orientation and magnitudes. Knowing the minimum horizontal stress allows a better mud weight window planning to reduce the chances of wellbore break-out and wellbore unintentional fracturing. The appropriate planning will minimize borehole instability and formation break-outs as shown in Figure 11. The formations most liable to instability are the weakest ones, which are those possessing the lowest in-situ shear, tensile strength, and stiffness modules. When wellbore penetrating such formations, especially ones drilled in non-principal stress directions, there is a strong contrast in the principal stresses. The wellbore may experience collapse or convergence problems particular with increased time of exposure to drilling mud or wellbore fluids (McLellan, 1996). 


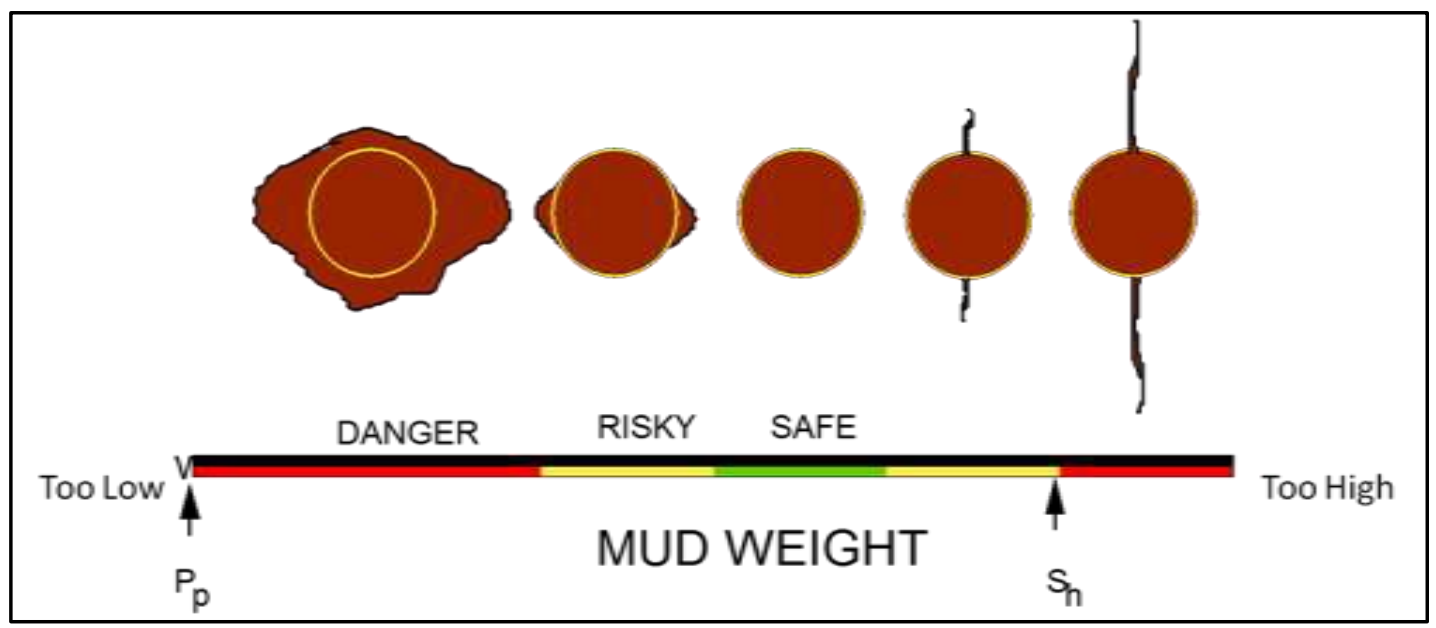

Figure 11: Minimum horizontal stress magnitude used in deciding safe mud weight window (Sundaram, K.M., 2010).

\subsection{Artificial Neural Network (ANN):}

Artificial neural network is the successful program of an active field of any research study that has developed greatly over the last few years. They are the computational models inspired by biological neural networks and are produced by estimated or convergent functions that are generally unknown. ANN contains a computational model based on the structure and functions of biological neural networks. These networks have produced good fitting non-linear functions and recognizing patterns. ANNs are produced in mining and civil departments, oil and gas, telecommunications industries and many different fields of study.

ANNs are applications of artificial intelligence that try to imitate the actions of the human brain and nervous system. ANN has provided three fundamental components: transfer function, network architecture and learning law (Simpson, 1990).

A typical ANN system consists of three layers as a system: the input layer, the hidden layer(s) and the output layer. These three layers are interconnected, and each layer consists of one or more nodes. Neurons in the input layer process data onto the hidden layer, which in turn transmits data to the output layer. ANNs pick up from data examples presented to them and utilize this data to adjust their weights in an effort to capture the relationship between the historical set of model inputs and corresponding outputs (Marraqu et al., 2015). 
Neurons use transfer function's option such as losing, tensing or purlin to produce their output values. The neural networks are trained by processing large values of datasets. The algorithms are available for training, but backpropagation algorithm is the most proficient one with ability to receive large input data and to solve complex problems. Using random weights, the network calculates some outputs. The calculated outputs are compared with the desired output to obtain the network error. The connecting weights reduce the errors in a process chosen as backpropagation using the same learning rule. Based on the training process, a pattern is presented to the network. The new weights are estimated using equations based on the old weights, the node input values, errors and the learning rate. This process should be repeated until the error is converged to a level defined by a cost function, such as mean square error (MSE). Network performance can be afflicted by retraining, rising the number of neurons, or using a larger training dataset. The training phase of the model has been successfully masterful; the performance of the trained model has to be validated producing an independent testing set.

The neural network considers a successful training, validation and testing mechanism that can be produced to predict datasets outputs for given inputs based on the learning pattern. Neural network simulation provides faster and accurate prediction compared to other methods of data analysis.

Random weights are assigned to the data set and fed to the hidden layer in a forward direction with the net input values in the hidden layer is given by Equation (11):

$p_{j}=\sum_{i=1}^{n} W_{i j} X_{i}$

Where $x_{i}$ represent the inputs, $w_{i j}$ are the weights connecting layer $i$ with layer $j$ and $n$ is the number of input units. 
The net output from the hidden layer is calculated using an activation function called the sigmoid function expressed in Equation (12).

$b_{j}=\frac{1}{\left(1+e^{-p_{j}}\right)}$

The total input to layer $\mathrm{k}$ (the output layer) is expressed as equation (13) shown below:

$$
U k=\sum_{i=1}^{n} W_{j k} b_{j}
$$

Where $w_{j k}$ is the weight connecting layer $j$ with layer $k$, and $b_{j}$ stands for the activation of a particular function is receiving neuron in layer $\mathrm{j}$.

The error is generated by comparing the actual output to the desired output. The error term in a given output, $\mathrm{k}$ is presented in Equation (14):

$$
\delta=d_{k}-\partial_{k}
$$

where $\delta$ is the error term, $d_{k}$ is the desired output and $\partial_{k}$ is the actual output. The total error function for the training pattern is given by Equation (15):

$$
0.5 \sum_{i=1}^{n}\left(d_{k}-\partial_{k}\right)
$$

where $d_{k}$ is the desired output and $\partial_{k}$ is the actual output.

Changes in weights are calculated using the learning rate, the error term, and the input units as illustrated in Equation (16):

$$
\nabla W_{j k}=\eta \delta_{k} x_{j k}
$$


Where $\nabla W_{j k}$ is the change in weight, $\eta$ is the learning rate, the error term is expressed as $\delta_{k}$, and $x_{j k}$ is the input unit.

The calculated weight changes are then used together with the old weights to Calculate new weights as shown in Equation (17):

$$
W^{N}{ }_{J K}=W_{j k}+\nabla W_{j k}
$$

\subsection{Mean Squared Error (MSE):}

MSE is defined or used for summarizing historical errors. The MSE is the average of the squared errors that measures the deviation of the forecasts from the actuals. The squaring process does not differentiate whether the error is positive or negative. The equation (18) may be expressed as:

$$
M S E=\frac{\sum_{i=1}^{n}\left(y_{i}-\hat{y}_{i}\right)^{2}}{n}
$$

where $\mathrm{n}=$ the number of data points in the subset.

MSE penalizes a forecasting technique much more heavily for larger errors than for smaller ones. (Tersine, R, 1994).

\section{Coefficient of Determination $\left(\mathbf{R}^{2}\right)$;}

The value of $R^{2}$ is determined to measure the proportion of the total variation of the dependent variable which is explained by the independent variables. The coefficient of determination is a standard measure of effectiveness for a regression model that measures how well the model fits the data. It is a range between zero and one that measures the squared correlation between the observed values of $y$ and the predictions produced by the model. The higher the number, the better the fit. The equation (19) defines the value of $R^{2}$ as:

$$
R^{2}=\frac{\sum_{j=1}^{n}\left[\left(y_{i}-\bar{y}\right)(\hat{y}-\hat{\bar{y}})\right]^{2}}{\left[\sum_{i=1}^{n}\left(y_{i}-\bar{y}\right)^{2}\right]\left[\sum_{i=1}^{n}\left(\hat{y}_{i}-\hat{\bar{y}}\right)^{2}\right]}
$$


Relative Absolute Error \%: is the relation between target and output prediction data of stresses given by Equation (20) as:

$$
\text { Relative Absolute Error } \%=\left[\frac{X_{\text {Output }}-X_{\text {Target }}}{X_{\text {Target }}}\right] \times 100
$$

\subsection{Neural Networks used for GeoMechanics Rocks and Stresses: -}

Fuzzy logs are an analytical technique in which various inputs are utilized to produce an in-situ stress profiles. These inputs are varied, and from the different log inputs, a single profile is generated. This variation of inputs allows for qualities in the rock, such as composition to be determined when a strict classification is not easily determined. Rock types that exist on the fringes of a given category can be identified as a result of these logs. These fuzzy logs can be used as input into other analytical methods, especially neural networks, in order to produce a more concrete profile of the in situ stresses of the area analyzed (Mohaghegh et al., 2004)

The results generated from this analysis allow for poroelastic modeling to occur in a manner consistent with existing mini-frac testing. Further data analysis through artificial neural networks, these systems mimic human cognition, allowing for advanced models to be produced and the relationship between separate data points to be made more concrete. The results of this paper showed a clear correlation for the relationship between horizontal and vertical stresses, presupposing that the vertical stress was nearly equivalent to the overburden. This correlational model could then be tied to additional inputs in the form of geomechanical and petrophysical data. These combined methods allow for a more accurate model than mere linear poroelastic determination would yield.

After comparing this data to mini-frac testing and the DSI data for the same strata, it was determined that the neural networks were effective in determining geomechanical and petrophysical data. These data points are then used to produce more accurate models of linear poroelasticity (Jamshidi et al, 2013). 
Artificial neural networks were methods utilized in identifying the in situ mechanical properties of various strata. These mechanical properties generated from artificial neural networks were relatively effective at providing the value of the modulus ratio and proved to produce a little error. After extensive testing of rocks strata of known ratios, it was determined that the neural networks were as effective as preexisting models in determining not on the modulus ratios, but several other pertinent measurements (unconfined compressive strength, modulus of elasticity, et cetera) in known wells. This was dependent upon the operational functions utilized as inputs, however, the after the network was trained, few errors could be produced (Havavi et al., 2016).

\subsection{Accurate In-Situ Stress Measurement During Drilling Operations: -}

Researchers (Kunze and Steiger, 1992) examined procedure used in obtaining in situ horizontal earth stress in carrying through drilling operations. The process was established and developed so as to obtain stress data that are necessary for obtaining wellbore stability modeling as well as for predicting and avoiding fracturing lost returns. Conventional leak off tests perform routinely so as to measure and test the integrity of casing cement jobs, not to measure earth stresses accurately. In this case, the most effective and important consideration made was to develop methods that could be implemented with relative ease and could minimize disturbance to drilling operations personnel. These processes are referred to as Extended Leak-off Test (XLOT).

In view of the need to preserve the stability of wellbore, the effort had been made to develop methods and procedures aimed at achieving wellbore stability in drilling, especially in water sensitive, weak shale. The article identifies that previous research in this area was focused on the chemical interaction of the process but in recent time, chemical and mechanical interaction that takes place during drilling have increased considerably. In understanding and applying this drilling procedure, drilling fluid density is an important design aspect of the process. Also, knowledge of earth stresses and rock strength are necessary requirements. 
In this process, the linear equation for calculating stresses are known and used, but their applications were limited by lack of data on in situ strength of shale. With the development of a method for determining downhole shale strength from the cutting analysis, things began to change.

A method was used in the successful drilling of the "Nesh Field Bloc 9/13 horizontal well and some other wells in block 913. All of these wells were designed with the aid of the wellbore stability simulations. Results produced through the use of these methods show that in a situation where a linear elastic analysis is combined with an estimate of the in-situ parameters and an appropriate failure criterion, in a normal condition, could produce a consistent quantitative tool for wellbore stability prediction. It shows the significance of a multidisciplinary approach in arriving at a close estimate of the in-situ parameters and other relevant data required for wellbore stability assessments which have been established and demonstrated. It also shows that good view of the in-situ stress state in an area results in safer and more cost-effective casing and cementing of the wellbore (Ottsen and Kwakwa, 1991). 


\section{CHAPTER 3 METHODOLOGY}

The drilling data was obtained from a well drilled in West Virginia and used to predict formation stresses with the help of a neural network program. The well had two sections with distinct directions as vertical and horizontal. Vertical and horizontal stresses changed within the vertical section but only the changes in horizontal stresses were significant in the lateral sections. The data recorded during drilling was separated into two parts representing measurements from vertical and lateral sections.

A new methodology was developed to predict how in-situ stresses depend on the drilling parameters by using artificial neural networks (MATLAB).

\subsection{Preparation:}

In the first step, the data was collected from well files including drilling data, vertical logs, and lateral sonic scanner. The data was checked for missing parameters if they existed and the minimum and maximum values are determined as shown in Tables $(1,2,3,4)$ below:

Table 1: Drilling Parameters Input Data of Vertical Well Section.

\begin{tabular}{|llll|}
\hline \multicolumn{3}{c|}{ Vertical well Data } \\
\hline No & Input parameters & Min Values & Max Values \\
\hline 1 & MD (ft) & 6804 & 7804 \\
\hline 2 & Weight on Bit (1000 lbs) & 0.7 & 100.2 \\
\hline 3 & Rotary Torque (ft-lbs) & 0.033 & 13.318 \\
\hline 4 & Bit RPM (rev/min) & 40 & 238 \\
\hline 5 & Stand Pipe Pressure (psi) & 213 & 2774 \\
\hline 6 & Total Pump Output (gallons/min) & 142 & 534 \\
\hline 7 & Rate of Penetration(ft/hr) & 2.76 & 291.98 \\
\hline 8 & Bulk Density (g/cc) & 2.43001 & 2.84885 \\
\hline 9 & Gamma Ray (GAPI) & 24.46347 & 614.26794 \\
\hline
\end{tabular}


Table 2: Stresses Parameters Target Data of Vertical Well Data Section

\begin{tabular}{|l|c|c|}
\hline \multicolumn{1}{|c|}{ Vertical well Data } & & \\
\hline Output parameters & Min Values & Max Values \\
\hline Horizontal Stress Gradient(psi/ft) & 0.72216 & 0.96234 \\
\hline Total Vertical Stress Gradient(psi/ft) & 1.16238 & 1.16489 \\
\hline
\end{tabular}

Table 3: Drilling Parameters Input Data of Horizontal Well Section

\begin{tabular}{|llll|}
\hline \multicolumn{4}{c|}{ Horizontal Well Data Section } \\
\hline No & Input Parameters & Min Values & Max Values \\
\hline 1 & MD(ft) & 7800 & 13810 \\
\hline 2 & TVD(ft) & 7447.6 & 7521 \\
\hline 3 & Weight on Bit (1000 lbs) & 0.3 & 42.6 \\
\hline 4 & Rotary Torque (ft.-lbs) & 4.63 & 19.02 \\
\hline 5 & Bit RPM (Rev/min) & 121 & 258 \\
\hline 6 & Stand Pipe Pressure (psi) & 1706 & 4180 \\
\hline 7 & Total Pump Output (gallons/min) & 77 & 492 \\
\hline 8 & Rate of Penetration (ft/hr) & 17 & 276.21 \\
\hline 9 & Gamma Ray (GAPI) & 75.62328 & 560.544 \\
\hline 10 & Bulk Density (g/cc) & 2.408362 & 2.849662 \\
\hline
\end{tabular}

Table 4: Stress Parameters Target Data of Horizontal Well Section.

\section{Horizontal Well Section}

\begin{tabular}{|llll|}
\hline No & Output Parameters & Min & Max \\
\hline 1 & Horizontal Stress Gradient (psi/ft) & Values & Values \\
\hline
\end{tabular}




\subsection{Normalization Data:}

This step is important when dealing with parameters of different units and scales. It concerns the normalization of data using all numeric variables in the range between zero and one $[0,1]$. One possible formula is given by equation (20) below:

$$
X_{n e w}=\frac{X-X_{\min }}{X_{\max }-X_{\min }}
$$

\section{Theory of Well Direction and Stresses: -}

The vertical and horizontal directions of wells have different levels of principal stresses and values during drilling. As Figure 12 shows, there is a relationship between drilling parameters and the type of rock produces that results with different values of stresses.

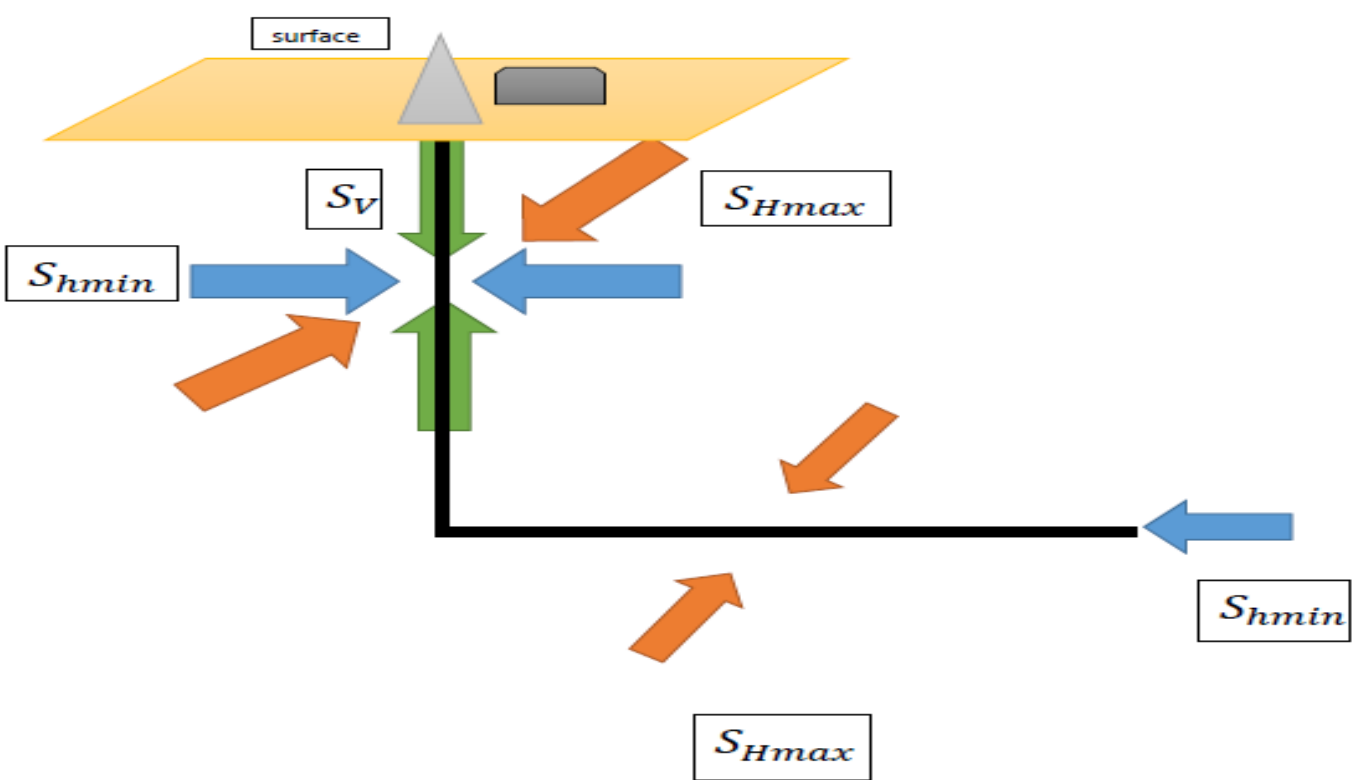

Figure 12: Vertical and horizontal well stress directions 


\section{CHAPTER 4}

\section{DISCUSSION OF RESULTS}

\subsection{Vertical Well Section (VWS) - Horizontal Stress (HS)}

\subsection{1 - Case 1 (Single layer ANN with 7 inputs)}

An artificial neural network (ANN1) model was developed to predict horizontal stresses in the vertical section of the wellbore. Model used seven input parameters from drilling operations consisting of measured depth, weight on bit, rotary torque, rotary speed, stand pipe pressure representing pump output pressure, total pump output volume, and rate of penetration with single hidden layer. Model output was the measured minimum horizontal stress values corresponding to the same measured depth. The data set consisted of 974 measurements along the vertical wellbore. Several combinations of samples were used as the training, validation and test sets to determine their optimum distributions. All three sets were selected at random from the total set and also repeated several times to eliminate bias in the sample selection process. Additionally, number of neurons for the single hidden layer was also varied between 5 and 25 to improve the predictions for minimum horizontal stress values. Table 5 below lists the distribution of samples and the corresponding neurons used for this ANN1 with each combination.

Table 5: Distribution of data sets and hidden neurons for ANN1

Run No.

\begin{tabular}{|c|c|}
\hline & No of Hidden Neurons \\
\hline 1 & 5 \\
\hline 2 & 5 \\
\hline 3 & 10 \\
\hline 4 & 10 \\
\hline 5 & 15 \\
\hline 6 & 15 \\
\hline 7 & 25 \\
\hline 8 & 25 \\
\hline
\end{tabular}

Training

Samples, \%

70

60

70

60

70

60

70

60
Validation Samples, Testing Samples, $\%$

15

20

15

20

15

20

15

20
$\%$

15

20

15

20

15

20

15

20 
Training of the network was performed by the Levenberg-Marquardt backpropagation algorithm. At the end of successful training, validation and testing, the runs were compared to determine the optimum network architecture. Selection of the best results were based on coefficient of determination $\left(R^{2}\right)$. For a perfect performance, the value of $R^{2}$ is one where predicted and measured values are the same. $R^{2}$ values obtained with ANN1 are listed in Table 6 . Based on the highest value of $R^{2}$ for the test set, run number six was selected as the optimum network architecture. Run six used 15 hidden neurons with 60\%,20\% and $20 \%$ distributions of the data set for training, validation and test sets, respectively.

Table 6: $R^{2}$ values for ANN1.

\begin{tabular}{|c|c|c|c|c|}
\hline Run No. & Training Set & Validation Set & Test Set & Total Set \\
\hline 1 & 0.7062 & 0.7000 & 0.6454 & 0.6942 \\
\hline 2 & 0.6670 & 0.7019 & 0.6757 & 0.6771 \\
\hline 3 & 0.7303 & 0.7137 & 0.7513 & 0.7316 \\
\hline 5 & 0.7343 & 0.6976 & 0.7488 & 0.7306 \\
\hline 6 & 0.7911 & 0.6880 & 0.7556 & 0.7712 \\
\hline 7 & 0.7565 & 0.7131 & 0.7667 & 0.7491 \\
\hline 8 & 0.7450 & 0.7230 & 0.7422 & 0.7410 \\
\hline
\end{tabular}

Results from the optimum run are given in Figure 13. Predicted and measured values of minimum, maximum, and average Minimum Horizontal Stress (MHS) are given in Table 7 for the best results obtained by ANN1. 

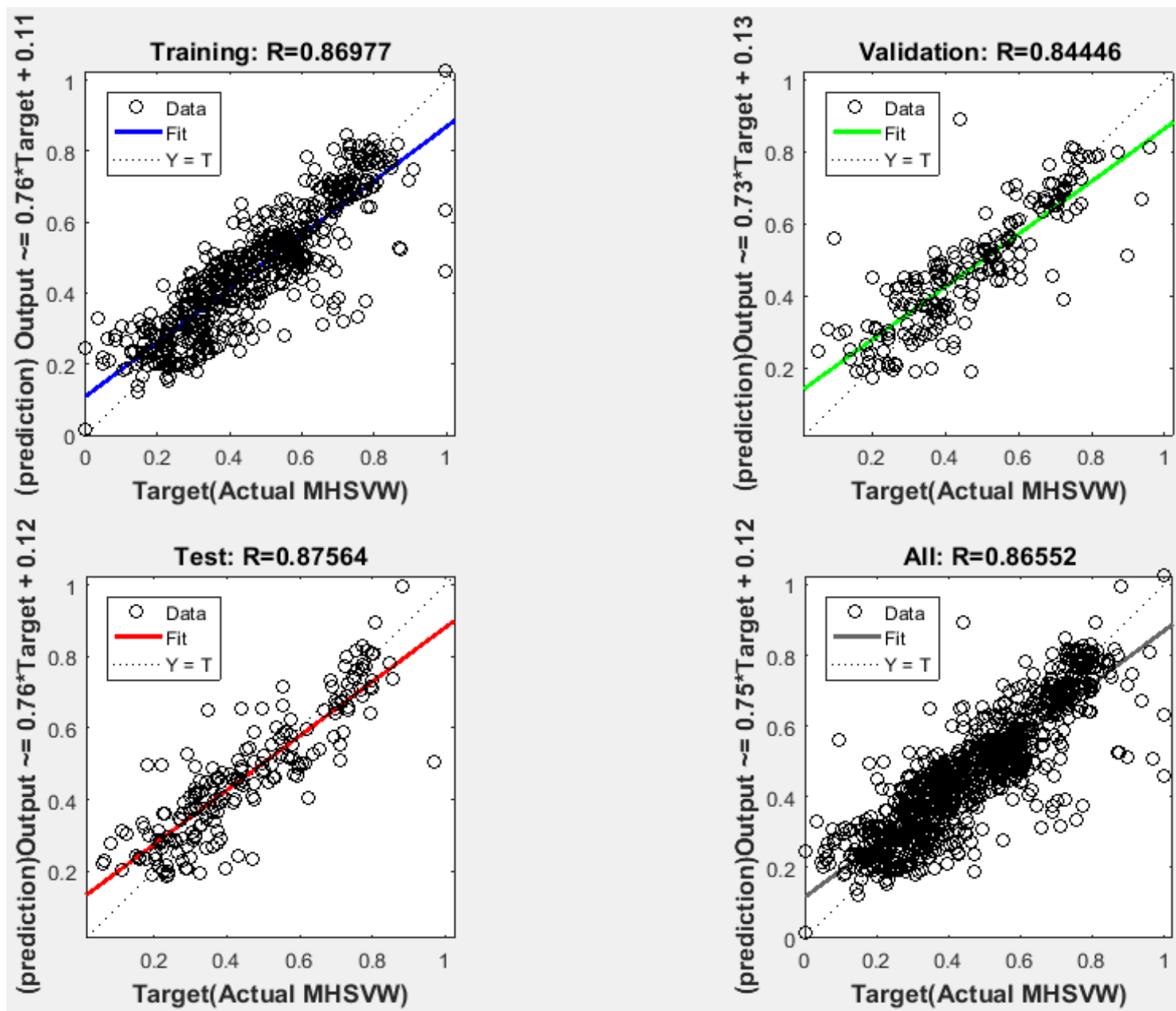

Figure 13: ANN1 results with best architecture design.

Table 7: Comparison of measured and predicted values of minimum, maximum, and average MHS Gradient in the vertical well (VW) section.

\section{Parameter}

Minimum of (MHSVW)

Maximum of (MHSVW)

Average of (MHSVW)

\section{Measured} Values, psi/ft

0.7222

0.9623

0.8368
Predicted Values, psi/ft

0.7254

0.9682

0.8337 


\subsubsection{Case 2 (Two-layer ANN with 7 inputs)}

Similar to Case 1 a new ANN2 was developed with two hidden layers to predict horizontal stresses in the vertical section of the wellbore using the same input parameters of measured depth, weight on bit, rotary torque, rotary speed, stand pipe pressure representing pump output pressure, total pump output volume, and rate of penetration. Model output was the measured minimum horizontal stress values.

The drilling data set containing measurements along the vertical wellbore was used to select several combinations of the training, validation and test sets to determine their optimum distributions. Table 8 below shows the distributions used with selected runs together with the number of neurons used for each data set.

Table 8: Distribution of data sets and hidden neurons for ANN2

Run No.

No of Hidden

Training

Samples, \%

5

1

2

3

4
70

70

70

70
Validation

Samples, \%

15

15

15

15
Testing

Samples, \%

15

15

15

15

The ANN2 was trained with feed-forward back-propagation because of its effectiveness for non-linear fittings. Coefficient of determination $\left(R^{2}\right)$ was used to select best results. For a perfect performance, the value of $R^{2}$ is one where predicted and measured values are the same. $R^{2}$ values obtained with ANN2 are listed in Table 9. Use of two hidden layers improved the prediction of stress values. The run 3 had the most efficient overall $R^{2}$ values of $0.8502,0.7687,0.7394$ and 0.8212 for the training, validation, test and total data sets, respectively. 
Table 9: $\mathrm{R}^{2}$ values for ANN2.

\begin{tabular}{|c|c|c|c|c|}
\hline Run No. & Training Set & Validation Set & Test Set & Total Set \\
\hline 1 & 0.7862 & 0.7443 & 0.7963 & 0.7814 \\
\hline 2 & 0.8131 & 0.8001 & 0.6792 & 0.7889 \\
\hline 3 & 0.8502 & 0.7687 & 0.7394 & 0.8212 \\
\hline 4 & 0.831 & 0.7589 & 0.6864 & 0.7993 \\
\hline
\end{tabular}

Results from the optimum run are given in Figure 14. Predicted and measured values of minimum, maximum, and average Minimum Horizontal Stress (MHS) are given in Table 10 for the best results obtained by ANN2.
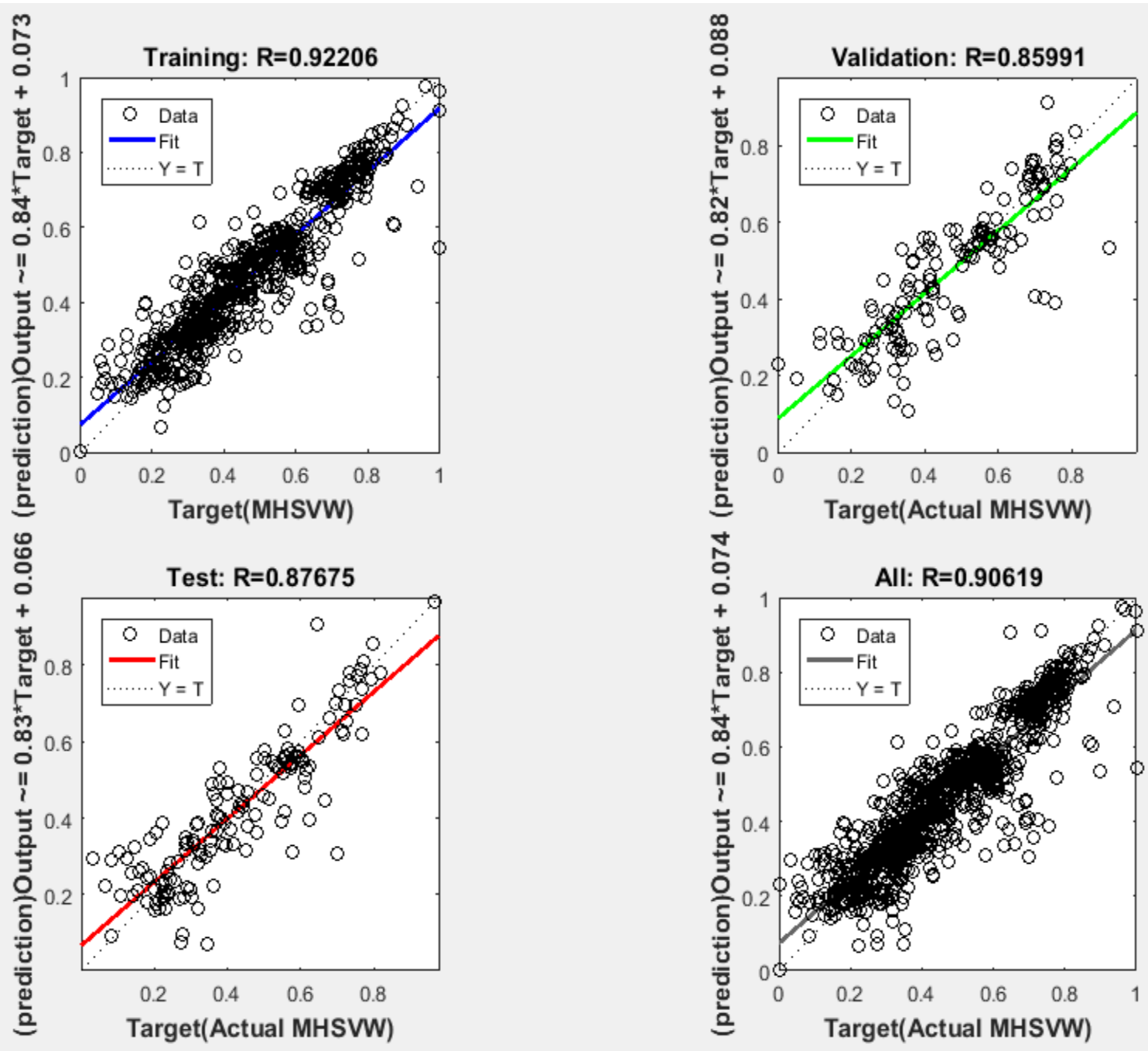

Figure 14:ANN2 results 
Table 10: Comparison of measured and predicted values of minimum, maximum, and average MHS .Gradient in the vertical well (VW) section

\begin{tabular}{|c|c|c|}
\hline Parameter & $\begin{array}{c}\text { Measured } \\
\text { Values, psi/ft }\end{array}$ & $\begin{array}{c}\text { Predicted } \\
\text { Values, psi/ft }\end{array}$ \\
\hline Minimum of (MHSVW) & 0.7222 & 0.7223 \\
\hline Maximum of (MHSVW) & 0.9623 & 0.9570 \\
\hline Average of (MHSVW) & 0.8368 & 0.8331 \\
\hline
\end{tabular}

\subsubsection{Case 3 (Two-layer ANN with 9 inputs)}

An additional network (ANN3) with two hidden layers was developed by adding two more parameters for the input data set. The purpose of this new model was to improve the prediction of ANN2 model. The additional parameters were gamma ray and bulk density and the output was minimum horizontal stress gradient. Based on the behavior of ANN2 same distribution of samples were used for ANN3 as $70 \%, 15 \%$, and $15 \%$ for training, validation and testing sets, respectively, with 15 hidden neurons (Table 11).

Table 11: Distribution of data sets and hidden neurons for ANN3.

\begin{tabular}{|c|c|c|c|c|}
\hline $\begin{array}{c}\text { Run } \\
\text { No. }\end{array}$ & $\begin{array}{c}\text { No of Hidden } \\
\text { Neurons }\end{array}$ & $\begin{array}{c}\text { Training } \\
\text { Samples, \% }\end{array}$ & $\begin{array}{c}\text { Validation } \\
\text { Samples, \% }\end{array}$ & $\begin{array}{c}\text { Testing } \\
\text { Samples, \% }\end{array}$ \\
\hline 1 & 15 & 70 & 15 & 15 \\
\hline
\end{tabular}

$R^{2}$ values obtained with ANN2 are listed in Table 12 .

Table 12: $R^{2}$ values for ANN3.

\begin{tabular}{|c|c|c|c|c|}
\hline Run No. & Training Set & Validation Set & Test Set & Total Set \\
\hline 1 & 0.8883 & 0.8405 & 0.8333 & 0.8707 \\
\hline
\end{tabular}


Results from the optimum run are given in Figure 15. The predictions improved with the addition of two new input parameters. The $R$ values were 0.94250 , $0.91678,0.91288$ and 0.93313 for the training, validation, test and overall data sets, respectively.
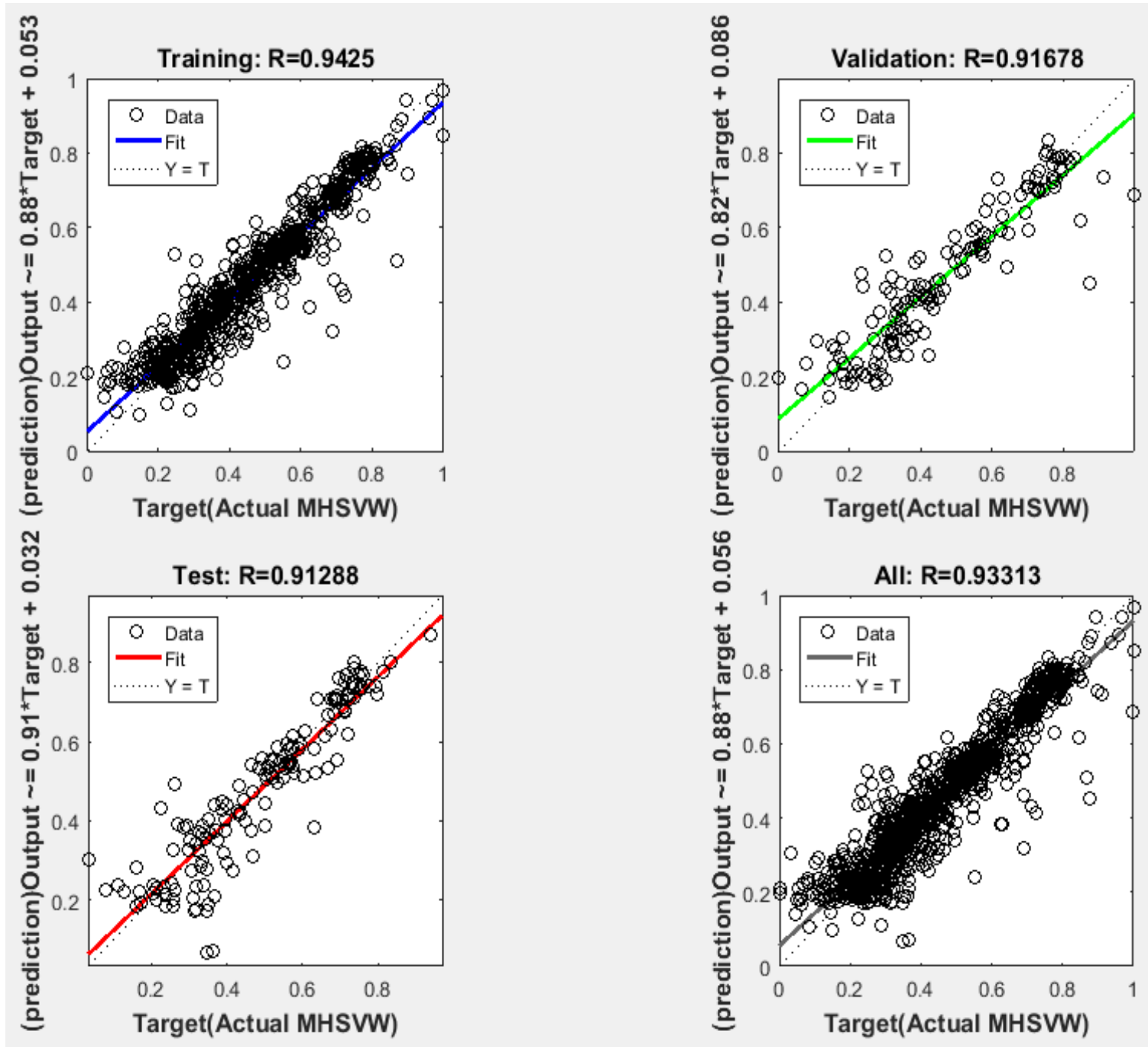

Figure 15: ANN3 results with optimum design.

Predicted and measured values of minimum, maximum, and average Minimum Horizontal Stress (MHS) are given in Table 13 for the best results obtained by ANN3 
Table 13: Comparison of measured and predicted values of minimum, maximum, and average MHS Gradient in the vertical well (VW) section.

\begin{tabular}{|c|c|c|}
\hline Parameter & $\begin{array}{c}\text { Measured } \\
\text { Values, psi/ft }\end{array}$ & $\begin{array}{c}\text { Predicted } \\
\text { Values, } \mathbf{p s i} / \mathbf{f t}\end{array}$ \\
\hline Minimum of (MHSVW) & 0.7222 & 0.7381 \\
\hline Maximum of (MHSVW) & 0.9623 & 0.9549 \\
\hline Average of (MHSVW) & 0.8368 & 0.8328 \\
\hline
\end{tabular}

\subsubsection{Summary of results for VWSHS}

Three ANNs were developed to predict minimum horizontal stress gradient for the vertical section of the wellbore. Major differences between models were the use of two hidden layers in two models and also including additional parameters in the prediction of output. Based on the ANN predicted results presented in Table 14, the predicted values were very close to the measurements in all three models.

Table 14: Comparison of measured and ANN predicted horizontal stress values in vertical section.

\begin{tabular}{|c|c|c|c|c|}
\hline & $\begin{array}{c}\text { Measured } \\
\text { Values } \\
\text { psi/ft }\end{array}$ & $\begin{array}{c}\text { ANN1 Predicted } \\
\text { Values } \\
\text { psi/ft }\end{array}$ & $\begin{array}{c}\text { ANN2 Predicted } \\
\text { Values } \\
\text { psi/ft }\end{array}$ & $\begin{array}{c}\text { ANN3 Predicted } \\
\text { Values } \\
\text { psi/ft }\end{array}$ \\
\hline $\begin{array}{c}\text { Minimum of } \\
\text { (MHSVW) }\end{array}$ & 0.7222 & 0.7254 & 0.7223 & 0.7381 \\
\hline $\begin{array}{c}\text { Maximum of } \\
\text { (MHSVW) }\end{array}$ & 0.9623 & 0.9682 & 0.9570 & 0.9549 \\
\hline $\begin{array}{c}\text { Average of } \\
\text { (MHSVW) }\end{array}$ & 0.8368 & 0.8337 & 0.8331 & 0.8328 \\
\hline
\end{tabular}

Predicted and measured horizontal stress values are plotted in Figure 16. 


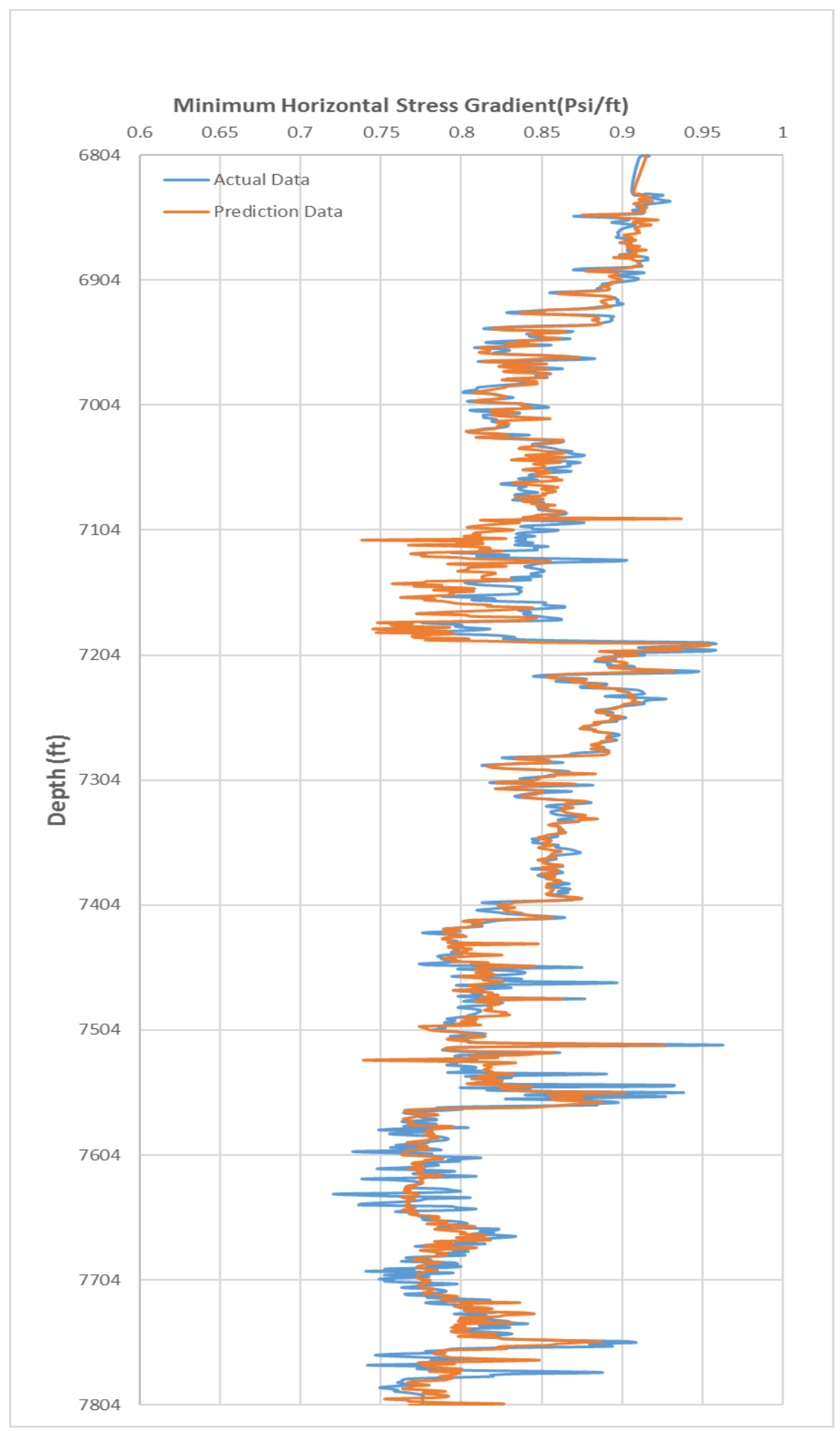

Figure 16: Two-layer ANN predicted and measured minimum horizontal stress gradient values (vertical well). 


\subsection{VWS - Vertical Stress (VS)}

\subsubsection{Case 4 (Single-layer ANN with 7 inputs)}

In this part of the study, an artificial neural network (ANN4) model was developed to predict the vertical stress in the vertical wellbore section. The ANN4 model consists of seven input parameters from drilling operations. These parameters are the measured depth, weight on bit, rotary torque, rotary speed, stand pipe pressure representing pump output pressure, total pump output volume, and rate of penetration with single hidden layer. Model output was the measured vertical stress values corresponding to the same measured depth. The data set consisted of 974 measurements along the vertical wellbore. Several combinations of samples were used as the training, validation and test sets to determine their optimum distributions. All three sets were selected at random from the total set and also repeated several times to eliminate bias in the sample selection process. Additionally, number of neurons for the single hidden layer was also varied between 5 and 25 to improve the predictions for minimum horizontal stress values. Table 15 below lists the distribution of samples and the corresponding neurons used for this ANN4 with each combination.

Table 15: Distribution of data sets and hidden neurons for ANN4

\begin{tabular}{|c|c|c|c|c|}
\hline $\begin{array}{c}\text { Run } \\
\text { No. }\end{array}$ & $\begin{array}{c}\text { No of Hidden } \\
\text { Neurons }\end{array}$ & $\begin{array}{c}\text { Training } \\
\text { Samples, \% }\end{array}$ & $\begin{array}{c}\text { Validation } \\
\text { Samples, \% }\end{array}$ & $\begin{array}{c}\text { Testing } \\
\text { Samples, \% }\end{array}$ \\
\hline 1 & 5 & 70 & 15 & 15 \\
\hline 2 & 5 & 60 & 20 & 20 \\
\hline 3 & 10 & 70 & 15 & 15 \\
\hline 4 & 10 & 60 & 20 & 20 \\
\hline 5 & 15 & 70 & 15 & 15 \\
\hline 7 & 15 & 60 & 20 & 20 \\
\hline 8 & 25 & 70 & 15 & 15 \\
\hline
\end{tabular}


The network was trained using by the Levenberg-Marquardt feed-forward, backpropagation algorithm. The runs were compared to determine the optimum network architecture at the end of successful training, validation and testing. The best results were selected based on the coefficient of determination $\left(R^{2}\right)$. The $R^{2}$ values obtained with ANN4 are listed in Table 16. Based on the highest value of $R^{2}$ for the test set, run number eight was selected as the optimum network architecture. Run eight used 25 hidden neurons with $60 \%, 20 \%$ and $20 \%$ distributions of the data set for training, validation and test sets, respectively.

Table 16: $\mathrm{R}^{2}$ values for ANN4.

\begin{tabular}{|c|c|c|c|c|}
\hline Run No. & Training Set & Validation Set & Test Set & Total Set \\
\hline 1 & 0.9980 & 0.9971 & 0.9971 & 0.9978 \\
\hline 2 & 0.9982 & 0.9975 & 0.9974 & 0.9979 \\
\hline 3 & 0.9995 & 0.9991 & 0.9991 & 0.9993 \\
\hline 4 & 0.9995 & 0.9991 & 0.9991 & 0.9993 \\
\hline 5 & 0.9995 & 0.9983 & 0.9989 & 0.9992 \\
\hline 7 & 0.9986 & 0.9981 & 0.9983 & 0.9984 \\
\hline 8 & 0.9994 & 0.9986 & 0.9981 & 0.9991 \\
\hline
\end{tabular}

Results from the optimum run are given in Figure 17. Predicted and measured values of minimum, maximum, and average total vertical stress (TVS) are given in Table 17 for the best results obtained by ANN4. 

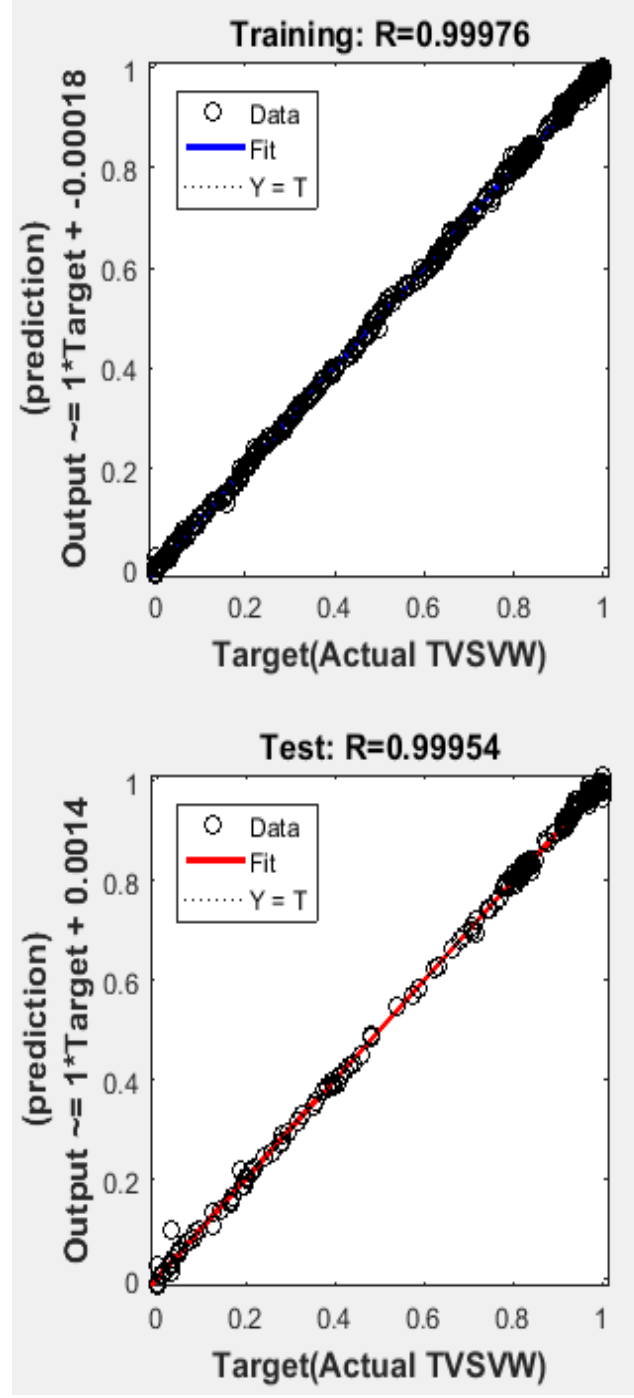
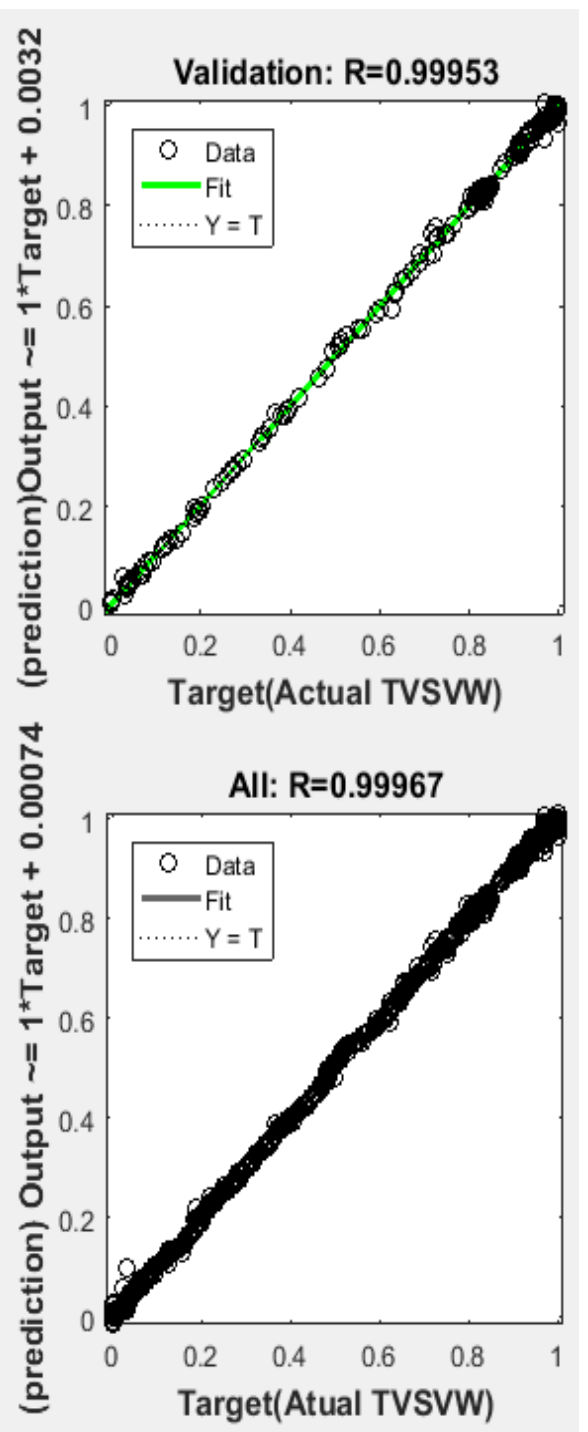

Figure 17: ANN4 results

Table 17: Comparison of measured and predicted values of minimum, maximum, and average TVS Gradient in the vertical well (VW) section

\begin{tabular}{|c|c|c|}
\hline Parameter & $\begin{array}{c}\text { Measured } \\
\text { Values, psi/ft }\end{array}$ & $\begin{array}{c}\text { Predicted } \\
\text { Values, psi/ft }\end{array}$ \\
\hline 8Minimum of (TVSVW) & 1.16238 & 1.16234 \\
\hline Maximum of (TVSVW) & 1.16489 & 1.16492 \\
\hline Average of (TVSVW) & 1.16406 & 1.16401 \\
\hline
\end{tabular}




\subsubsection{Case 5 (Two-layer ANN with 7 inputs)}

Similar to Case 4 a new ANN5 was developed with two hidden layers to predict the vertical stress in the vertical wellbore section using the same input parameters of measured depth, weight on bit, rotary torque, rotary speed, stand pipe pressure representing pump output pressure, total pump output volume, and rate of penetration. Model output was the total vertical stress values.

The drilling data set containing measurements along the vertical wellbore was used to select several combinations of the training, validation and test sets to determine their optimum distributions. Table 18 below shows the distributions used with selected runs together with the number of neurons used for each data set.

Table 18: Distribution of data sets and hidden neurons for ANN5

\begin{tabular}{|c|c|c|c|c|}
\hline $\begin{array}{c}\text { Run } \\
\text { No. }\end{array}$ & $\begin{array}{c}\text { No of Hidden } \\
\text { Neurons }\end{array}$ & $\begin{array}{c}\text { Training } \\
\text { Samples, \% }\end{array}$ & $\begin{array}{c}\text { Validation } \\
\text { Samples, \% }\end{array}$ & $\begin{array}{c}\text { Testing } \\
\text { Samples, \% }\end{array}$ \\
\hline 1 & 5 & 70 & 15 & 15 \\
\hline 2 & 10 & 70 & 15 & 15 \\
\hline 3 & 15 & 70 & 15 & 15 \\
\hline 4 & 25 & 70 & 15 & 15 \\
\hline
\end{tabular}

The ANN5 was trained with feed-forward back-propagation because of its effectiveness for non-linear fittings. Coefficient of determination $\left(R^{2}\right)$ was used to select best results. The $\mathrm{R}^{2}$ values obtained with ANN5 are listed in Table 19. The use of two hidden layers improved the prediction of vertical stress values. The run 4 had the most efficient overall $R^{2}$ values of $0.9998,0.9994,0.9988$ and 0.9995 for the training, validation, test and total data sets, respectively.

Table 19: $R^{2}$ values for ANN5.

\begin{tabular}{|c|c|c|c|c|}
\hline Run No. & Training Set & Validation Set & Test Set & Total Set \\
\hline 1 & 0.9978 & 0.9977 & 0.998 & 0.9978 \\
\hline 2 & 0.9998 & 0.9987 & 0.9991 & 0.9995 \\
\hline 3 & 0.9996 & 0.9992 & 0.9986 & 0.9994 \\
\hline 4 & 0.9998 & 0.9994 & 0.9988 & 0.9995 \\
\hline
\end{tabular}


Results from the optimum run are given in Figure 18. Predicted and measured values of minimum, maximum, and average total vertical stress (TVS) are given in Table 20 for the best results obtained by ANN5.
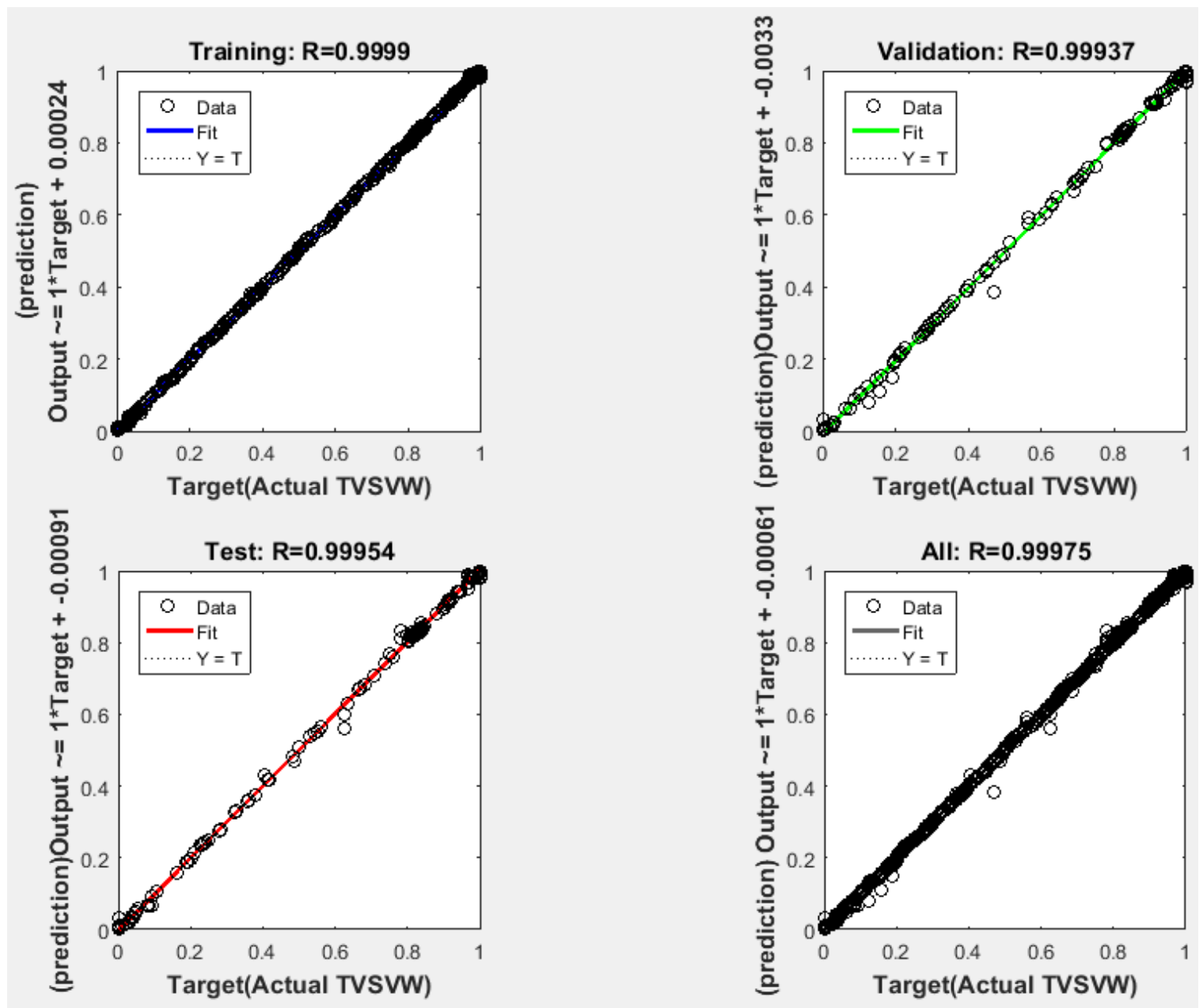

Figure 18:ANN5 results

Table 20: Comparison of measured and predicted values of minimum, maximum, and average TVS Gradient in the vertical well (VW) section

\begin{tabular}{|c|c|c|}
\hline Parameter & $\begin{array}{c}\text { Measured } \\
\text { Values, psi/ft }\end{array}$ & $\begin{array}{c}\text { Predicted } \\
\text { Values, psi/ft }\end{array}$ \\
\hline Minimum of (TVSVW) & 1.16238 & 1.16239 \\
\hline Maximum of (TVSVW) & 1.16489 & 1.16489 \\
\hline Average of (TVSVW) & 1.16406 & 1.16401 \\
\hline
\end{tabular}




\subsubsection{Case 6 (Two-layer ANN with 9 inputs)}

An additional network (ANN6) with two hidden layers was developed by adding two more parameters for the input data set. The purpose of this new model was to improve the prediction of ANN6 model. The additional parameters were gamma ray and bulk density and the output was total vertical stress (TVS) gradient. Based on the behavior of ANN6 same distribution of samples were used as $70 \%$, $15 \%$, and $15 \%$ for training, validation and testing sets, respectively, with 10 hidden neurons (Table 21).

Table 21: Distribution of data sets and hidden neurons for ANN6

\begin{tabular}{|l|l|l|l|l|l|}
\hline $\begin{array}{l}\text { Run } \\
\text { No. }\end{array}$ & $\begin{array}{l}\text { No of Hidden } \\
\text { Neurons }\end{array}$ & $\begin{array}{l}\text { Training } \\
\text { Samples, \% }\end{array}$ & $\begin{array}{l}\text { Validation } \\
\text { Samples, \% }\end{array}$ & \multicolumn{2}{l|l}{$\begin{array}{l}\text { Testing } \\
\text { Samples, \% }\end{array}$} \\
\hline 1 & 10 & & 70 & & 15
\end{tabular}

Results from the optimum run are given in Figure 19. The predictions improved with the addition of two new input parameters. The $\mathrm{R}^{2}$ values were 0.9998 , $0.9990,0.9992$ and 0.9996 for the training, validation, test and overall data sets, respectively (Table 22 ).

Table 22: $R^{2}$ values for ANN6

\begin{tabular}{|c|c|c|c|c|}
\hline Run No. & Training Set & Validation Set & Test Set & Total Set \\
\hline 1 & 0.9998 & 0.9990 & 0.9992 & 0.9996 \\
\hline
\end{tabular}



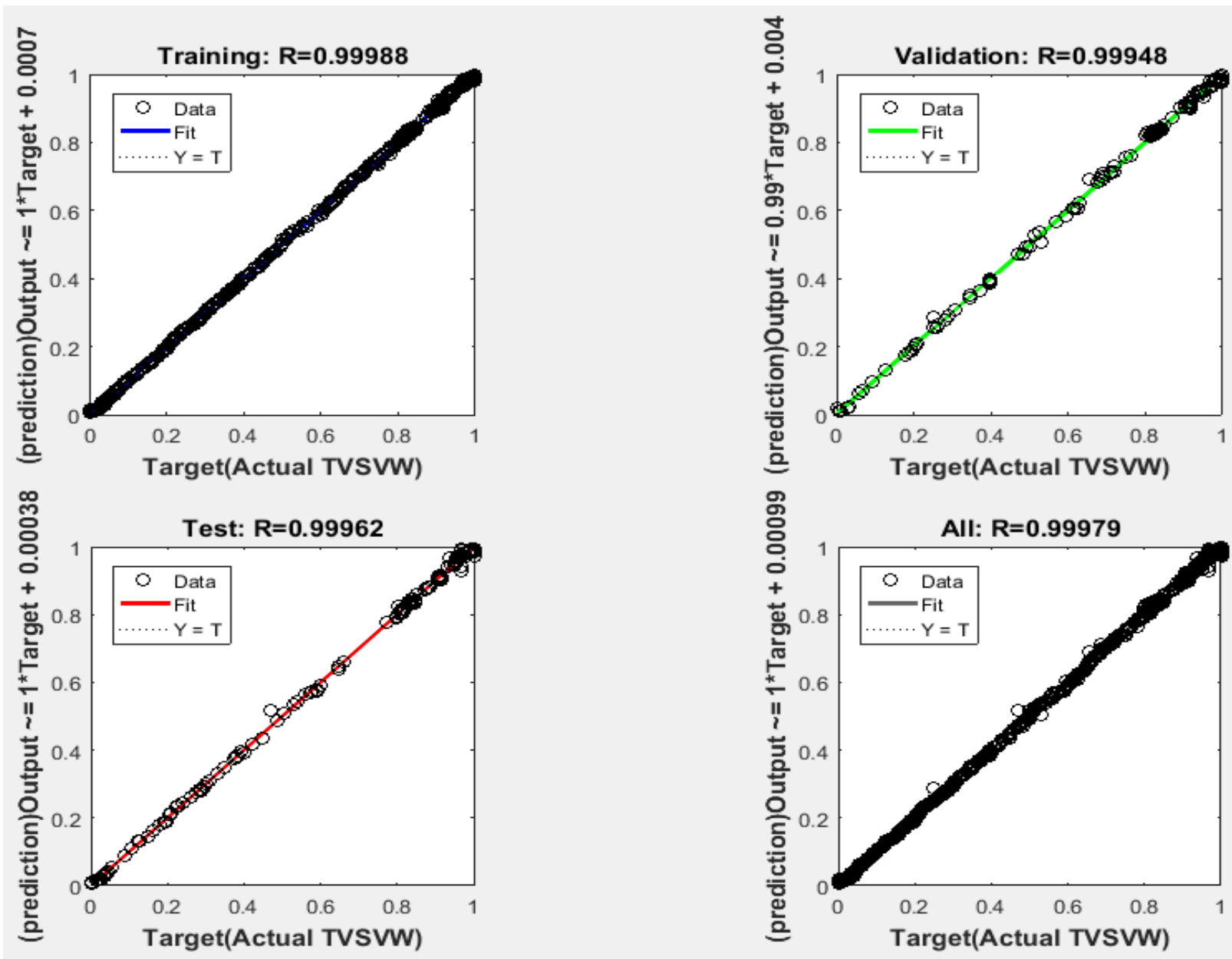

Figure 19:ANN6 results with optimum design.

Predicted and measured values of minimum, maximum, and average total vertical stress (TVS) are given in Table 23 for the best results obtained by ANN6.

Table 23: Comparison of measured and predicted values of minimum, maximum, and average TVS Gradient in the vertical well (VW) section.

\begin{tabular}{|c|c|c|}
\hline Parameter & $\begin{array}{c}\text { Measured } \\
\text { Values, psi/ft }\end{array}$ & $\begin{array}{c}\text { Predicted } \\
\text { Values, psi/ft }\end{array}$ \\
\hline Minimum of (TVSVW) & 1.16238 & 1.16240 \\
\hline Maximum of (TVSVW) & 1.16489 & 1.16489 \\
\hline Average of (TVSVW) & 1.16406 & 1.16401 \\
\hline
\end{tabular}




\subsubsection{Summary of results for VWSVS}

The total vertical stress gradient predictions for the vertical section of the wellbore was conducted with three different ANNs. One model had one hidden layer and two models had two-hidden layers. Several runs were conducted with each model using different number of neurons and the best results are compared in Table 24 below for the predicted total vertical stress values. The predicted values were very close to each other in all three models and also to the measurements.

Table 24: Comparison of measured and ANN predicted vertical stress values in vertical section.

\begin{tabular}{|c|c|c|c|c|}
\hline Parameter & $\begin{array}{c}\text { Measured } \\
\text { Values } \\
\text { psi/ft }\end{array}$ & $\begin{array}{l}\text { ANN4 Predicted } \\
\text { Values } \\
\text { psi/ft }\end{array}$ & $\begin{array}{c}\text { ANN5 Predicted } \\
\text { Values } \\
\text { psi/ft }\end{array}$ & $\begin{array}{c}\text { ANN6 Predicted } \\
\text { Values } \\
\text { psi/ft }\end{array}$ \\
\hline $\begin{array}{c}\text { Minimum of } \\
\text { (TVSVW) }\end{array}$ & 1.16238 & 1.16234 & 1.16239 & 1.16240 \\
\hline $\begin{array}{l}\text { Maximum of } \\
\text { (TVSVW) }\end{array}$ & 1.16489 & 1.16492 & 1.16489 & 1.16489 \\
\hline $\begin{array}{c}\text { Average of } \\
\text { (TVSVW) }\end{array}$ & 1.16406 & 1.16401 & 1.16401 & 1.16401 \\
\hline
\end{tabular}

Figure 20 shows predicted and measured vertical stress values in the vertical section of the wellbore. 


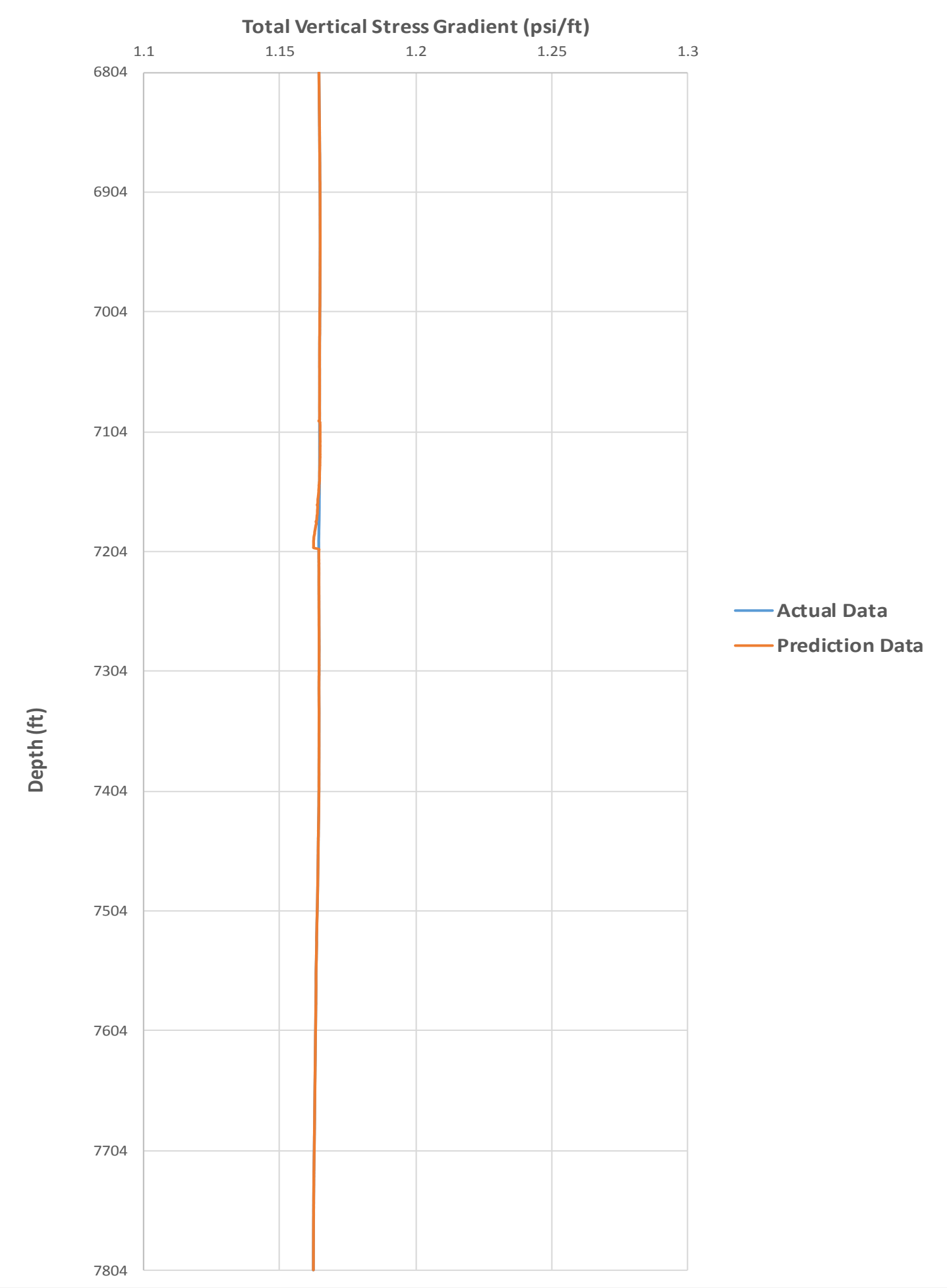

Figure 20: Two-layer ANN predicted and measured total vertical stress gradient values (vertical well). 


\subsection{Horizontal Well Section (HWS) - Horizontal Stress (HS) \\ 4.3.1. Case 7 (Two-layer ANN with 9 inputs)}

An artificial neural network (ANN7) with two hidden layers was developed by adding two more parameters for the input data set. The additional parameters were gamma ray and bulk density and the output was the horizontal stress gradient. The distribution of samples were used as $70 \%, 15 \%$, and $15 \%$ for training, validation and testing sets, respectively, with 15 hidden neurons (Table 25).

Table 25: Distribution of data sets and hidden neurons for ANN7.

\begin{tabular}{c|c|c|c|c|}
$\begin{array}{c}\text { Run } \\
\text { No. }\end{array}$ & $\begin{array}{c}\text { No of Hidden } \\
\text { Neurons }\end{array}$ & $\begin{array}{c}\text { Training } \\
\text { Samples, \% }\end{array}$ & $\begin{array}{c}\text { Validation } \\
\text { Samples, \% }\end{array}$ & $\begin{array}{c}\text { Testing } \\
\text { Samples, \% }\end{array}$ \\
\hline 1 & 15 & 70 & 15 & 15 \\
\hline
\end{tabular}

Results from the optimum run are given in Figure 21. The predictions improved with the addition of two new input parameters. The $R^{2}$ values were 0.8878 , $0.8856,0.8892$ and 0.8875 for the training, validation, test and overall data sets, respectively (Table 26 ).

Table 26: R2 values for ANN7.

\begin{tabular}{|c|c|c|c|c|}
\hline Run No. & Training Set & Validation Set & Test Set & Total Set \\
\hline 1 & 0.8878 & 0.8856 & 0.8892 & 0.8875 \\
\hline
\end{tabular}



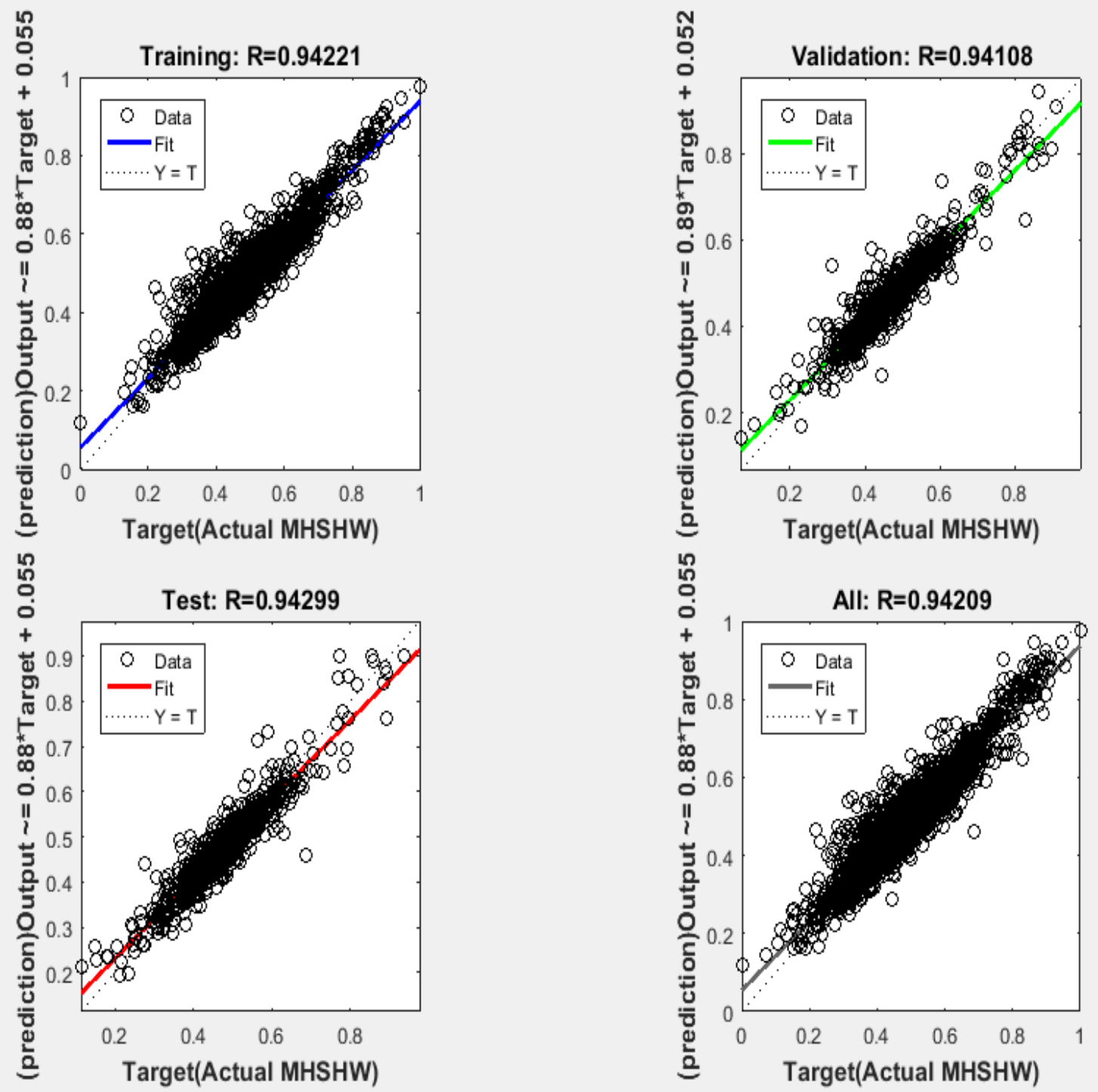

Figure 21:ANN7 results with optimum design.

Predicted and measured values of minimum, maximum, and average Horizontal Stress (MHS) are given in Table 27 for the best results obtained by ANN7

Table 27: Comparison of measured and predicted values of minimum, maximum, and average MHS Gradient in the horizontal well (HW) section.

\section{Parameter}

Minimum of (MHSHW)

Maximum of (MHSHW)

Average of (MHSHW)
Measured Values, psi/ft

0.7222
1.1018
0.9011

\section{Predicted} Values, psi/ft

1.0930

0.9010 


\subsubsection{Case 8 (Two-layer ANN with 10 inputs)}

An artificial neural network (ANN8) with two hidden layers was developed by adding three more parameters for the input data set. The additional parameters were gamma ray, bulk density, and the measured depth and the output was the horizontal stress gradient. The distribution of samples were $70 \%, 15 \%$, and $15 \%$ for training, validation and testing sets, respectively, with 15 hidden neurons (Table 28).

Table 28: Distribution of data sets and hidden neurons for ANN8.

\begin{tabular}{c|c|c|c|c|}
$\begin{array}{c}\text { Run } \\
\text { No. }\end{array}$ & $\begin{array}{c}\text { No of Hidden } \\
\text { Neurons }\end{array}$ & $\begin{array}{c}\text { Training } \\
\text { Samples, \% }\end{array}$ & $\begin{array}{c}\text { Validation } \\
\text { Samples, \% }\end{array}$ & $\begin{array}{c}\text { Testing } \\
\text { Samples, \% }\end{array}$ \\
\hline 1 & 15 & 70 & 15 & 15 \\
\hline
\end{tabular}

Results from the optimum run are given in Figure 22. The predictions improved with the addition of two new input parameters. The $R^{2}$ values were 0.9159 , $0.8691,0.8703$, and 0.9016 for the training, validation, test and overall data sets, respectively (Table 29 ).

Table 29: $\mathrm{R}^{2}$ values for ANN8.

\begin{tabular}{|c|c|c|c|c|}
\hline Run No. & Training Set & Validation Set & Test Set & Total Set \\
\hline 1 & 0.9159 & 0.8691 & 0.8703 & 0.9016 \\
\hline
\end{tabular}



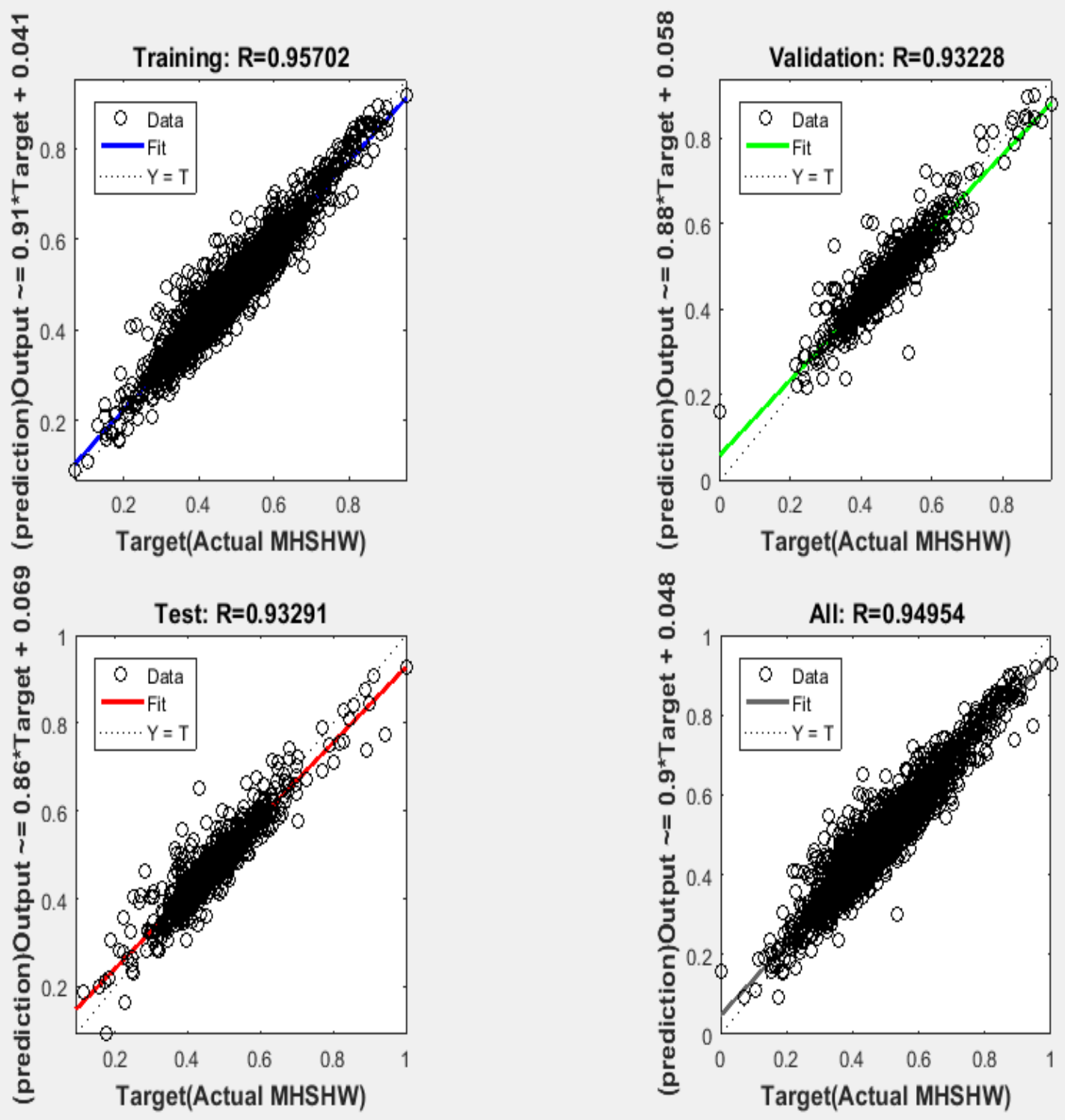

Figure 22: ANN8 results with optimum design.

Predicted and measured values of minimum, maximum, and average Horizontal Stress (MHS) are given in Table 30 for the best results obtained by ANN8.

Table 30: Comparison of measured and predicted values of minimum, maximum, and average MHS Gradient in the horizontal well (HW(section.

\begin{tabular}{|c|c|c|}
\hline Parameter & $\begin{array}{c}\text { Measured } \\
\text { Values, psi/ft }\end{array}$ & $\begin{array}{c}\text { Predicted } \\
\text { Values, psi/ft }\end{array}$ \\
\hline Minimum of (MHSVW) & 0.7222 & 0.7570 \\
\hline Maximum of (MHSVW) & 1.1018 & 1.0746 \\
\hline Average of (MHSVW) & 0.9011 & 0.9013 \\
\hline
\end{tabular}




\subsubsection{Summary of results for HWSHS}

Two ANNs were developed to predict minimum horizontal stress gradient for the horizontal section of the wellbore. Major differences between models with twohidden layers were the use of an additional input for the second model. Based on the ANN predicted values given in Table 31 , the predicted values were very close to the measurements in the two models. Figure 23 shows predicted and measured horizontal stress values in the horizontal section of the wellbore.

Table 31: Comparison of measured and ANN predicted horizontal stress values in horizontal section.

\begin{tabular}{|c|c|c|c|}
\hline & $\begin{array}{c}\text { Measured } \\
\text { Values } \\
\text { psi/ft }\end{array}$ & $\begin{array}{c}\text { ANN7 Predicted } \\
\text { Values } \\
\text { psi/ft }\end{array}$ & $\begin{array}{c}\text { ANN8 Predicted } \\
\text { Values }\end{array}$ \\
\hline Minimum of (MHSHW) & 0.7222 & 0.7676 & 0.7570 \\
\hline Maximum of (MHSHW) & 1.1018 & 1.0930 & 1.0746 \\
\hline Average of (MHSHW) & 0.9011 & 0.9010 & 0.9013 \\
\hline
\end{tabular}

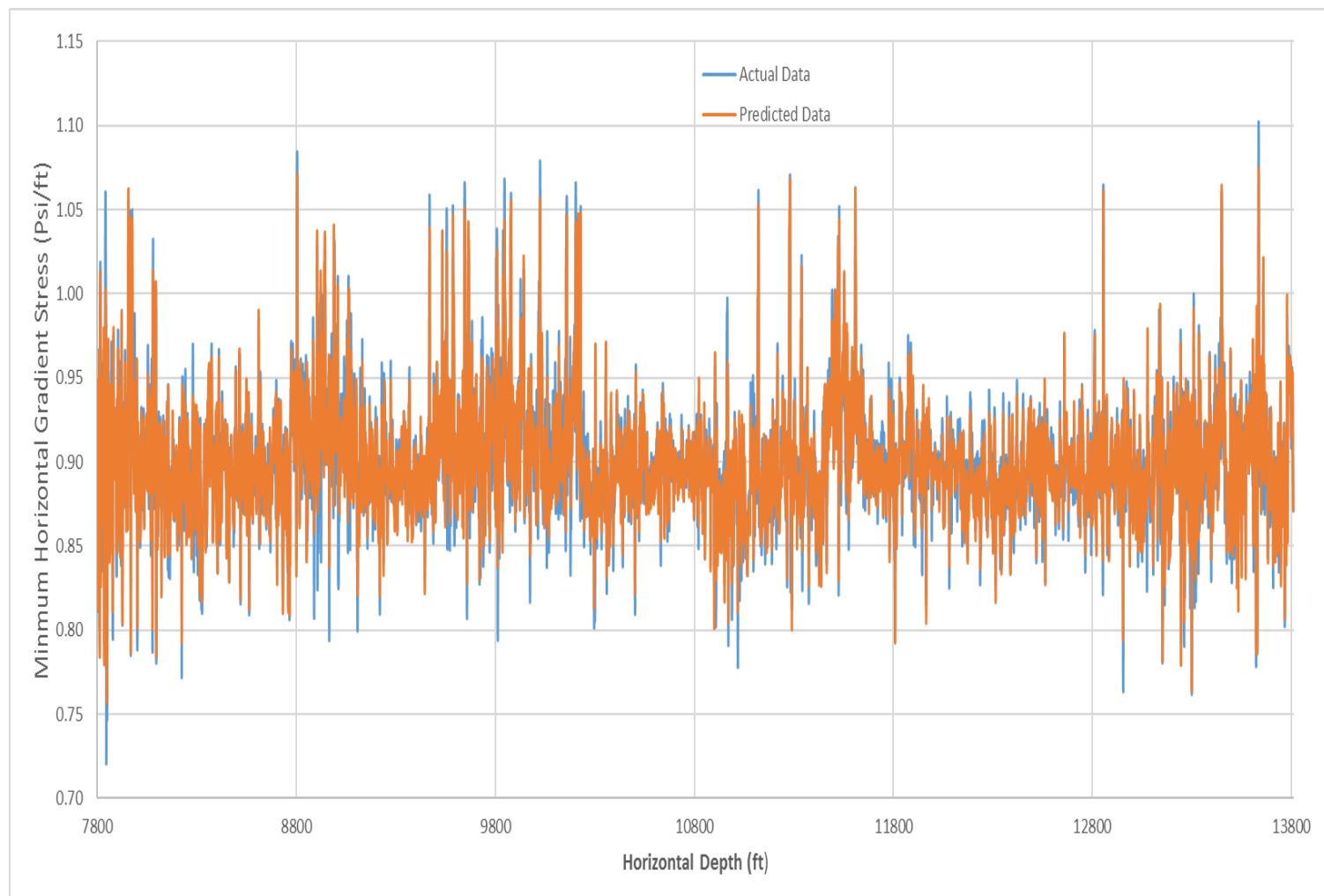

Figure 23: Two layer ANN predicted and measured minimum horizontal stress gradient values (horizontal well). 


\section{CHAPTER 5}

\section{CONCLUSIONS}

In this study, several ANN models were successfully developed to predict formation stresses in a Marcellus shale well. Specifically, models consider vertical and lateral section of the wellbore to estimate minimum horizontal stress gradient and vertical stress gradient in the vertical section and minimum horizontal stress in the horizontal section. With this approach, the stress values can be estimated during the drilling process giving the driller a valuable information. The drilling data used in models included measured depth, true vertical depth, pump circulation rate, rate of penetration, rotary speed, rotary torque, and weight on bit. In some models additional inputs were used to determine their impact on the predictions. These additional parameters were gamma ray and bulk density.

Several ANN models were developed with one and two layers but two layer models were more effective in the prediction of output parameters. Most of the ANNs developed in this study used two-layer design with different number of hidden neurons. Models successfully estimated the vertical stress values in the vertical section and horizontal stress values in vertical and lateral sections of the well.

The total vertical stress gradient estimation in the vertical well section was obtained with the two-hidden layer ANN model using 10 hidden neurons. The data sets were consisted of $70 \%$ for training, $15 \%$ for validation, and $15 \%$ for testing. Two hidden layers model had an $\mathrm{R}^{2}$ value of 0.999500 for all data sets.

Best results for horizontal stress gradient estimation in the vertical well section was obtained by the two-layer ANN model. The model used 15 hidden neurons and consisted of 70\% training data set, 15\% validation data set, and $15 \%$ test data set. The final $R^{2}$ value was 0.870732 .

In the case of horizontal stress gradient estimation in the lateral section of the well, best results were obtained by the two-layer ANN with 15 hidden neurons. The data set distribution was $70 \%, 15 \%$, and $15 \%$ for training, validation, and test sets. The $\mathrm{R}^{2}$ value was 0.901626 when stress values in the lateral section were determined. 


\section{REFERENCES}

Aadnoy, B. S. \& hansen, A. K. 2005. Bounds on In-Situ Stress Magnitudes Improve Wellbore Stability Analyses. Society of Petroleum Engineers.

Aadnoy, B. S. \& looyeh, R. 2011. Petroleum Rock Mechanics: Drilling Operations and Well Design. B“Art of Directional Drilling: Basic Terminologies." N.p., n.d. Web. 19 Mar. 2017.

Beard, T., 2011, Fracture Design in Horizontal Shale Wells-Data Gathering to Implementation, EPA Hydraulic Fracture Workshop, March 10th-11th, 2011, Web.

http://water.epa.gov/type/groundwater/uic/class2/hydraulicfracturing/upload/fracturedesigninh orizontalshalewells.pdf'

Carnegie, A., Thomas, M., Efnik, M. S., Hamawi, M., Akbar, M. \& Burton, M. 2002. An Advanced Method of Determining In-situ Reservoir Stresses: Wireline Conveyed Micro-Fracturing. Society of Petroleum Engineers.

Cook, J., R.A. Frederiksen, K. Hasbo, S. Green, A. Judzis, J.W. Martin, R. Suarez-Rivera, J. Herwanger, P. Hooyman, Don Lee, S. Noeth, C. Sayers, N. Koutsabeloulis, R. Marsden, M.G. Stage and C.P. Tan, (2007), "Rocks Matter; Ground Truth in Geomechanics", Oilfield Review, autumn 2007, p. 36-55.

Desroches, J., and A. L. Kurkjian. "Applications of Wireline Stress Measurements." SPE Reservoir Evaluation and Engineering, 1999: 451-461.

Drill-Tek MWD. Oil Industry Dictionary Glossary of Terms. 2001. http://www.drilltekmwd.com/dictonary/glossary_of_terms_b.html (accessed 2012).

Economides, M.J. and K.G. Nolte, (2010), "Reservoir Stimulation" Page 105 - 120, Wiley and sons Inc.

Fjær, E., Holt, R. M., Horsrud, P., Raaen, A. M. \& Risnes, R. 2008. Petroleum Related Rock Mechanics, Elsevier Science.

Gronseth, J. M., P. R. Kry (1983), Instantaneous shut in pressure and its relationship to the minimum in-situ stress, Proc. Hydraulic Fracturing Stress Measurements, Monterey p. 55-60, National Academy Press, Washington, DC.

Havavi, M. T., Abdideh, M., Eremin, M. O., Lukianova, R., Vorobev, A. V., \& Vorobeva, G. R. (2016). Estimation of in-situ horizontal stresses using the linear poroelastic model and minifrac test results in tectonically active area. Russian Journal of Earth Sciences, 16(4).

Heidbach, O., Tingay, M., Barth, A., Reinecker, J., Kurfeß, D. and Müller, B., 2008, The World Stress Map database release 2008 doi:10.1594/GFZ.WSM.Rel2008. 
Hooke, R., and J. B. Hansen, (2005), Stress analysis Strain Analysis and shearing of Soils book title, The Engineering Foundations, McGraw-Hill, New York, NY.

Hubbert, M.K. and D.G. Willis, (1957) "Mechanics of Hydraulic Fracturing Trans.AIME, 210-153166.

Jamshidi, E., Arabjamaloei, R., Hashemi, A., Ekramzadeh, M. A., \& Amani, M. (2013). Real-time Estimation of Elastic Properties of Formation Rocks Based on Drilling Data by Using an Artificial Neural Network. Energy Sources, Part A: Recovery, Utilization, and Environmental Effects, 35(4), 337-351.

Khandelwal, Manoj and Singh, T.N., 2009. Prediction of blast-induced ground vibration using artificial neural network. International Journal of Rock Mechanics and Mining Sciences, Volume 46, Issue 7, pp. 1214 - 1222.

Kunze, K. R., \& Steiger, R. P. (1992, January). Accurate in-situ stress measurements during drilling operations. In SPE Annual Technical Conference and Exhibition. Society of Petroleum Engineers.

Marcellus Center for Outreach and Research, 2008, The Pennsylvania State University, University Park, PA http://www.marcellus.psu.edu/resources/maps.php.(Marcellus Shale Map -

Marcellus Shale Maps - PA, NY, WV, OH, 2017)

http://www.marcellusshales.com/marcellusshalemap.html.

McLellan, P. "Assessing the Risk of Wellbore Instability in Horizontal and Inclined Wells." The Journal of Canadian Petroleum Technology, 1996: 21-32.

Mohaghegh, S. D., Popa, A., Gaskari, R., Wolhart, S., Siegfreid, R., \& Ameri, S. (2004, January). Determining in-situ stress profiles from logs. In SPE Annual technical Conference and Exhibition. Society of Petroleum Engineers.

Nieto, J., R. Badry, J. Kovacs, D. Ellis, O. Faivre, and L. Mosse. "Improved Density Logging in Hot, Rugose Carbonate Formations." Petrophysics, 2005: 173-187.

Ottesen, S., \& Kwakwa, K. A. (1991, January). A multidisciplinary approach to in-situ stress determination and its application to wellbore stability analysis. In SPE/IADC Drilling Conference. Society of Petroleum Engineers.

Simpson, P.K.,1990. Artificial Neural Systems. Foundation, Paradigms, Applications, and Implementations. Pergamon Press, New York, NY.

Sinha, B.K., Wang, J., Kisra, S., Li, J., Pistre, V., Bratton, T., Sanders, M., Jun, C. "Estimation of Formation Stresses Using Borehole Sonic Data." SPWLA 49th Annual Logging Symposium. Edinburgh: SPWLA, 2008. 1-16.

Short, J. A. (1993). Introduction to directional and horizontal drilling. Penn well Corporation. 
Sundaram, K.M., Three - Phase VSP and Geomechanics Integration for ONGC Deep water wildcat Well. Eastern India: Schlumberger, 2010. Print.

Teichrob, R., A. Kustamsi, G. Hareland, U. Odiegwu (2010), Estimating In Situ Stress Magnitudes and Orientations in an Albertan Field in Western Canada, ARMA 10-224, Proceedings of the 44th US Rock Mechanics Symposium and 5th U.S.- Canada Rock Mechanics Symposium, Salt Lake City, UT June 27-30 2010 p. 210-218, CRMS, Thailand.

Tersine, R., Principles of Inventory and Materials Management Fourth Edition Prentice Hall, 1994.

Thorsen, K. 2011. In situ stress estimation using borehole failures - Even for inclined stress tensor. Journal of Petroleum Science and Engineering, 79, 86-100.

U.S. Energy Information Administration (2016). "US crude oil and natural gas proved Reserves" in federal and non-federal areas. Washington, DC: Congressional Research Service 20585.www.eia.gov.

Valko, Peter, and Michael J. Economides, (1995), "Hydraulic Fracture Mechanics" NJ, USA, Wiley and sons Inc.

Wahl, J. S., J. Tittman, C. W. Johnstone, and R. P. Alger. "The Dual Spacing Formation Density Log." Journal of Petoleum Technology, 1964: 1411-1416.

Warren, W. E., and C. W. Smith. "In-Situ Stress Estimates from Hydraulic Fracturing and Direct Observation of Crack Orientation." Journal of Geophysical Research, 1985: 6829-6839.

WVU National Research Center, et al. A Geologic Play Book for Utica Shale Appalachian Basin Exploration. Morgantown: Coordinated by Appalachian Oil \& National Gas Consortium at WVU , 2015.print.

Yu, H., Lian, Z., Lin, T., Zhu, K., "Experimental and numerical study on casing wear in a directional well under in situ stress for oil and gas drilling." Journal of Natural Gas Science and Engineering 35 (2016): 986-996.

Zagorski, W. A., Wrightstone, G. R., Bowman, D. C., 2012, The Appalachian Basin Marcellus Gas Play: Its History of Development, Geologic Controls on Production, and Future Potential as a World-class Reservoir, in J.A. Breyer ed., Sale Reservoirs- Giant Resources for the 21st Century: AAPG Memoir 97, p. 172-200.

Zoback, M. D. Reservoir Geomechanics. Cambridge University Press, 2007. 